Ljubljana

\title{
KOMMUNIKATIVE FUNKTION DER GEGENWÄRTIGEN DEUTSCHEN UMGANGSSPRACHE, NACHGEWIESEN AN REISEBERICHTEN AUS DER PRESSE
}

Diese Zusammenfassung der gleichnamigen Dissertation* weist die folgende Gliederung auf:

\section{Einleitung}

2. Zum Begriff der (kommunikativen) Funktion in der Linguistik

3. Zum Wesen und zur Funktion der gegenwärtigen deutschen Umgangssprache

4. Faktoren und Bedingungen der Kommunikation

5. Mustertextanalyse

5.0. Der Mustertext

5.1. Die kommunikativen Determinanten des Mustertextes

5.2. Die Sprachanalyse des Mustertextes (auszugsweise)

5.3. Umgangssprachliche Ausdrucksmittel

5.4. Die Distribution der umgangssprachlichen Ausdrucksmittel im Mustertext

5.5. Kommunikative Funktionen umgangssprachlicher Ausdrucksmittel Klassifikation

6. Vergleichende Analyse

7. Abschließende Bemerkungen

\section{EINLEITUNG}

Das Ziel dieser Dissertation ist es, die kommunikative Funktion der gegenwärtigen deutschen Umgangssprache in Reiseberichten der Presse zu untersuchen. Ich möchte feststellen, zu welchem Zweck in der Textsorte Reiseerzählung umgangssprachliche Ausdruckselemente verwendet werden. Die Umgangssprache ist

* Die Dissertation wurde am 11.9.1990 mit Erfolg vor der Kommission Prof. Dr. Siegfried Heusinger (zugleich Mentor), Prof. Dr. Janez Stanonik, Prof. Dr. Janez Orešnik verteidigt. Die Zusammenfassung wurde mit finanzieller Unterstützung des Forschungsinstituts (Znanstveni inštitut) der Philosophischen Fakultät in Ljubljana veröffentlicht, das die Arbeit an der Dissertation im Rahmen seines Forschungsprojekts förderte. 
u.a. deshalb Gegenstand dieser Untersuchung, weil (auch) in der deutschen Gegenwartssprache einige tradierte Verhältnisse zwischen den einzelnen Existenzformen der Sprache (vgl. HARTUNG 1977: 69) nur noch eine beschränkte Geltung zu haben scheinen und weil besonders die Umgangssprache dabei an Bedeutung zuzunehmen scheint (vgl. KAEMPFERT 1985: 1833, HARTUNG-SCHÖNFELD 1981: 79 f.), ohne daß diese Problematik jedoch ausreichend untersucht wäre (vgl. SCHMIDT et al. 1981: 251, LÖSCH 1986: 114).

Die Pressesprache ist dabei sehr geeignet für die Untersuchung "der Integration umgangssprachlicher Mittel in die Literatursprache" (LANGNER 1986: 103), weil sie stark verbreitet ist bei grundsätzlich dispersem Publikum, weil sie überregional ist (sein kann) (Auswahl der Zeitungen bzw. Zeitschriften!), weil sie alle Lebensbereiche beherrscht, weil sie innovativ ist (vgl. LÜGER 1983: 22), weil sie einen starken Einfluß auf das Sprachgefühl der Leser hat und somit eine normgebende Funktion besitzt. (Vgl. NELLEN 1986: 101.) So beeinflußt sie die Entwicklung der Sprache nicht selten entscheidender als die Belletristik. (Vgl. NELLEN 1986: 101,117, POLENZ 1987: 101.)

Die zentrale Aufgabe dieser Dissertation besteht jedoch darin, den Zusammenhang von objektiver Realität, aus der unwillkürlich die Determinanten des Kommunikationsprozesses hervogehen, und der Art der Vertextung, d. h. der Textbildung, die mit diesen Determinanten zusammenhängt, aufzuzeigen. Das geschieht unter besonderer Berücksichtigung der Umgangssprache. Es ist ein Anliegen dieser Arbeit, das Verhältnis zwischen außersprachlichen Gegebenheiten bei der Textgestaltung einerseits und der sprachlichen Objektivation des Textes andererseits aufzuhellen. Aus diesem Verhältnis geht nämlich auch die Logik der Verwendung und der Funktion der Umgangssprache hervor.

Eine solche Zielsetzung wurde u. a. von dem Anliegen geprägt, daß die Resultate dieser Untersuchung (wenigstens mittelbar) auch zur Vervollkommnung didaktischer Verfahren im Fremdsprachenunterricht - konkret der deutschen Sprache beitragen mögen. Es sollte auf verschiedene Funktionalstile der deutschen Gegenwartssprache hingewiesen werden, das Bewußtmachen der Verwendung verschiedener Ausdrucksmöglichkeiten sollte die kommunikative Kompetenz derer festigen, denen das Deutsche keine Muttersprache ist. Auf diese Art sollte auch im Fremdsprachenunterricht, insbesondere auf der Universitätsebene, allmählich die Grundstufe elementaren Unterscheidens zwischen "richtig" und "falsch" überwunden werden, ein elastisches Beherrschen aller Registermöglichkeiten des sprachlichen Instrumentariums sollte auch einem Nichtmuttersprachler souveräne Kommunikation ihm Rahmen kommunikativer Normen ermöglichen und somit sein Gefühl für den Stil und für die Sprachkultur schärfen.

Hauptsächlich lehne ich mich in dieser Untersuchung (insbesondere in ihrem empirischen Teil) an das Instrumentarium der funktional-kommunikativen Sprachbeschreibung (vgl. SCHMIDT et al. 1981). Obwohl ein solcher Ausgangspunkt eine relativ enge Orientierung an der DDR-Version der tätigkeitsbezogenen Sprach- 
beschreibung bedeutet, ist durch einige operationelle Vorteile dieser Version diese Arbeitseingrenzung gerechtfertigt (vgl. HELBIG 1986: 227).

Die empirische Analyse will u.a. ermitteln, an welchen Stellen im Text umgangsssprachliche Ausdrucksmittel verwendet sind, sie will die zweckmäßige Abhängigkeit der umgangssprachlichen Ausdrucksmittel von der gesamten kommunikativen Konstellation des Textes deuten und den dialektischen Zusammenhang von kommunikativen Parametern des Textes und seiner sprachlichen Realisation aufzeigen. Auf diesem dialektischen Zusammenhang beruht die Klassifikation der kommunikativen Funktionen der umgangssprachlichen Ausdrucksmittel. Sich an das alles heranzutasten ist nur unter der Bedingung möglich, daß zugleich verschiedene Ebenen des Sprachsystems beachtet werden, und zwar sein Wortschatz wie auch seine morphologischen, syntaktischen und stilistischen Besonderheiten.

Die empirische Analyse des Mustertextes ist somit in erster Linie als qualitative Darstellung komplexer Mechanismen aufzufassen, die bei der Entstehung eines Textes eine Rolle spielen, unter besonderer Berücksichtigung der Verwendung und der Funktion von umgangssprachlichen Ausdrucksmitteln. Diese qualitative Seite der Untersuchung ist zwar mit gewissen statistischen Ausrechnungen untermauert, ohne jedoch eine repräsentative statistische Studie anstreben zu wollen. Dasselbe trifft auch für die vergleichende Analyse der acht Texte zu, die nicht auf Einzelheiten aus der Mustertextanalyse eingeht, sondern in einem etwas weiteren Rahmen den Geltungsgrad einiger wesentlicher Erkenntnisse der Mustertextanalyse zu prüfen sucht.

\section{ZUM BEGRIFF DER (KOMMUNIKATIVEN) FUNKTION IN DER LINGUISTIK}

Der Funktionsbegriff wurde in der Sprachwissenschaft ziemlich unterschiedlich verwendet und ist terminologisch auch heute noch nicht eindeutig festgelegt. Dasselbe gilt für den Begriff der kommunikativen Funktion, der besonders in der Kommunikationstheorie gebräuchlich ist. Beide Begriffe können sich auf relative Ergebnisse der Kommunikationsprozesse, d. i. auf Texte, beziehen oder aber auf sprachliche Ausdrucksmittel, die als Mittel bei der Textgestaltung verwendet werden. Im 1. Fall wird die kommunikative Funktion als Zielgerichtetheit der Handlungen bzw. der Texte definiert, im 2. Fall aber als Zweckbestimmtheit der Verwendung einzelner Sprachmittel (SCHMIDT 1982: 15). ${ }^{<1>}$ In letzter Zeit wurde diese, im Prinzip akzeptierbare Auffassung der kommunikativen Funktion mit neuen Erkenntnissen überbaut:

a) daß auch die Zielgerichtetheit der Texte i. w. S. als Zweckbestimmtheit der Verwendung des Textes als Mittels zur Erreichung eines übergeordneten Kommunikationsziels verstanden werden kann;

b) daß die kommunikative Funktion sowohl als Zielgerichtetheit (des Textes i.e.S.) als auch als Zweckbestimmtheit (der Ausdrucksmittel) sich auf eine direkte und indirekte Art zeigt. Ich beziehe mich dabei in erster Linie auf jene versteckten Einwirkungen auf den Adressaten, die bei der spontanen Perzeption eines Textes, bei 
der unmittelbaren Analyse der kommunikativen Funktion aus verschiedenen Gründen nicht so leicht zu erfassen sind. ${ }^{<2>}$ Der Sender versucht dabei,im Text absichtlich eine doppelte kommunikative Absicht zu kodieren, bzw. er läßt seine wahre kommunikative Absicht unter Anwendung verschiedener Mittel nicht direkt vordringen, indem die eine (scheinbare) kommunikative Absicht (nach Möglichkeit) direkt und sofort erkennbar sein sollte, die andere (tatsächliche) kommunikative Absicht, "der Textsinn" (BIEBERLE 1987: 199), jedoch durch bewußte Täuschung (nach Möglichkeit) unidentifiziert bleiben möge, obwohl sie im konkreten Text (mittelbar) die kommunikative Haupt- oder Nebenrolle erfüllen sollte. Damit in Zusammenhang zu bringen ist logischerweise die zentrale Rolle des strategisch-operativen Vorgehens bei der Realisierung von Kommunikationsabsichten. Bei der Vertextung von Kommunikationsabsichten können somit verschiedene Kombinationen des Transparenten und Versteckten zum Vorschein kommen, wobei sich freilich auch der Grad der Aufrichtigkeit und Ehrlichkeit seitens des Textproduzenten ändert: von dem lediglichen Bestreben, größere Wirksamkeit zu erzielen - sei es in der belletristischen Literatur (ästhetische Effekte), sei es in alltäglichen Gebrauchstexten des wirtschaftlichen (Werbung) oder politischen Lebens (Agitation und Propaganda) bis hin zu regelrechtem Manipulieren mit dem Adressaten. ${ }^{<3}$ Das bedeutet eine zusätzliche Herausforderung für die intellektuelle Anstrengung des Rezipienten bei der Textdekodierung sowie für den Textproduzenten bei der Textgestaltung;

c) daß man einer sog. rezeptiven Komponente der kommunikativen Funktion Rechnung tragen muß, wobei unter dem Begriff rezeptive Komponente der kommunikativen Funktion unvorhersehbare Wirkungen der Texte bzw. der Ausdrucksmittel auf den Adressaten zu verstehen sind; darin ist eine der Grundlagen für die Vervollkommnung des Kommunikationsmechanismus und für das entsprechende Ausbauen des Sprachsystems zu suchen.

Die kodierte (Text)funktion wird in der Regel vom Andressaten dekodiert. Allerdings fallen dabei die beabsichtigte und die realisierte Einwirkung häufig auseinander. Jede kommunikative Situation ist eine einmalige und praktisch unwiederholbare Kombination verschiedener Faktoren und Bedingungen, die auch unerwarteter-, zufälliger- und überraschenderweise miteinander kombiniert werden können. Es stimmt zwar, daß die Mehrheit dieser Kombinationen und wechselseitiger Einwirkungen gesellschaftlich konventionalisiert und gefestigt, d. h. normiert ist, es müssen jedoch auch Unerwartetes und Zufälliges als Komponenten der kommunikativen Funktion von kommunikativen Prozessen bzw. von Ausdrucksmitteln beachtet werden. (Vgl. GROSSE-NEUBERT 1982, RONNEBERGER-SIBOLD 1980, SCHILDT 1987). Wenn wir die Kommunikation als tätigkeitsbezogene Interaktion auffassen, so ist der Begriff der Absicht eigentlich als erstes Element, als Einleitepol eines ambivalenten, dialektischen Spannungsgefüges "Absicht-Wirkung" zu betrachten. Dabei ist - wie oben ausgeführt - eine Übereinstimmung oder Nichtübereinstimmung beider Bestandteile (entgegengesetzter Pole) möglich, und dies führt zu verschiedenen Konsequenzen. Eine Teilwirkung des Textes oder der Ausdrucksmittel kann sich folglich im funktionalen Sinn der bewußten kommunikativen Ausgangsabsicht entziehen. Der kommunikative Effekt auf den Adres- 
saten kann der ursprünglichen Absicht mitunter sogar vorgreifen, wenn es sich um eine ausdrücklich spontane Ausdrucksweise handelt. Bisweilen kann gegenseitiges Einwirken verschiedener Kommunikationsfaktoren in der Folge zu nachträglichen, sich erst nach abgeschlossenem Kommunikationsprozeß einstellenden unerwarteten und überraschenden Assoziationen führen. ${ }^{<4>}$ Eben diese unvorhersehbaren Auswirkungen in der geplanten Kommunikation als einer Ganzheit sowie beim Gebrauch einzelner Ausdrucksmittel zur Realisierung des Kommunikationsprozesses (ich bezeichne das mit dem Begriff rezeptive Komponente der kommunikativen Funktion) gehören m.E. zu den Triebkräften der funktionsmäßigen Entfaltung des Sprachsystems und der Vervollständigung der sprachlichen Kommunikation;

d) daß auch eine Komponente der kommunikativen Funktion existiert, die auf den Adressaten angewiesen ist und deshalb die Funktion für den Rezipienten genannt wird. Die Funktion für den Rezipienten kann mit den Erwartungen, Absichten und Interessen des Rezipienten, wenn dieser einen bestimmten Text wählt, übereinstimmen oder nicht. Damit hängt der Grad der Nützlichkeit/Förderlichkeit der Texte zusammen (vgl. HEUSINGER 1987: 886 f.). Diesen Grad der Nützlichkeit des Textes beurteilt der Adressat aus seiner Perspektive, was in letzter Konsequenz auch dazu führen kann, daß "ein ungeeigneter und dem Rezeptionsziel nicht dienlicher Text ... im allgemeinen vom Rezipienten als Rezeptionsobjekt auch nicht akzeptiert /wird/" (HEUSINGER 1987a: 195). Der Adressat, obwohl mittelbar und passiv, beeinflußt seinerseits aúch den Verlauf des Kommunikationsprozesses.

\section{ZUM WESEN UND ZUR FUNKTION DER GEGENWÄRTIGEN DEUTSCHEN UMGANGSSPRACHE}

Eine ganzheitliche Erfassung des Phänomens der deutschen Umgangssprache, das noch nicht endgültig erforscht ist, ist unter Beachtung verschiedener Sprachvarietäten als Ausprägungen des Variationscharakters der (deutschen Gesamt)Sprache möglich. Dabei scheint am meisten akzeptabel das dynamische Modell der Erfassung einzelner Varietäten ${ }^{<5>}$ (Erscheinungsformen, Existenzformen) der Sprache. ${ }^{<8>}$ Dieses sieht in einer Sprachvarietät - auch in der Umgangssprache - die Kombination eines grundlegenden sprachlichen Substrats einerseits, das allen Sprachvarietäten mehr oder weniger gemeinsam ist, und typischer sprachlicher Besonderheiten andererseits, die variieren, je nachdem, um welche Sprachvarietät es sich handelt. Nur eine solche phänomenologische Betrachtungsweise ermöglicht es, die Logik fließender Übergänge von einer Sprachvarietät in eine andere zu verstehen ${ }^{<7}$, zugleich aber auch die Vielschichtigkeit innerhalb einzelner Sprachvarietäten, die auch für die Umgangssprache charakteristisch ist. Bei einer Sprachvarietät als solcher geht es also nicht in erster Linie um die Alternative im Sinne von Vorhanden- oder Nichtvorhandensein einzelner sprachlicher Elemente, sondern vielmehr um prozentuale Relationen (vgl. BERTHOLD 1968: 334), Fokusse, Häufigkeit, Konzentrationen, Schwerpunkte, Tendenzen u. d. m.

Die Feststellung, daß die moderne deutsche Umgangssprache historisch gesehen 
ein Ausgleichsprodukt zwischen der Literatursprache und den Mundarten ist und daß ihre Entstehung durch die gesellschaftliche Entwicklung und die veränderten Kommunikationsbedürfnisse bedingt ist, ermöglicht das Erfassen der Funktion, die die Umgangssprache im allgemeinen in der gegenwärtigen Kommunikation besitzt. In der Vergangenheit hat es mehrere Umgangssprachen gegeben. Diese waren regional eingegrenzt und stellten einen auf den Prinzipien der Diglossie beruhenden Kode dar, der von den sozial "niedriger" stehenden Sozialschichten nur in besonderen kommunikativen Situationen anstatt der Dialekte verwendet wurde.

Die qualitative Entwicklung des Phänomens Umgansssprache verlief offenbar in folgenden Stufen:

- Umgangssprache wird allmählich auch schriftlicher Kode; sie dominiert in der Alltagskommunikation;

- Umgangssprache wird mehr und mehr überregional;

- Umgangssprache verliert allmählich ihre ursprüngliche vorwiegend sozial-stigmatisierende Eigenschaft und übernimmt psycho-sozial bedingte kommunikative Funktionen (vgl. HARTUNG-SCHÖNFELD 1981: 91);

- Umgangssprache wird im Zusammenhang mit allen möglichen Gegenstandsund Inhaltskomplexen verwendet; es gibt kaum noch inhaltliche Einschränkungen in bezug auf die Verwendung der Umgangssprache wie in früheren Jahren;

- Umgangssprache ist nicht mehr ausschließlich Domäne des Alltagsverkehrs, sondern sie dringt in beinahe alle Funktionalstile ein;

- es bildet sich allmählich auch ein Normsystem der Umgangssprache heraus; dieses ist aber noch nicht so exakt ausgebaut wie jenes der Literatursprache und der Mundarten.

Das Resultat dieses Prozesses ist also der, daß heute ohne besondere Vorbehalte von e i n e $r$ deutschen Umgangssprache gesprochen werden $k_{a n n}{ }^{<>}$, die überregionale Verwendung findet und eine situative, psychologisch geprägte Varietät darstellt, die funktional mit der Literatursprache gleichwertig sein kann. Die Umgangssprache ist nicht mehr ausschließlich die Domäne der gesprochenen Sprache, sondern sie dringt auch in literatursprachliche schriftliche Texte ein und beeinflußt so auch die Norm der Literatursprache. Es läßt sich behaupten, daß hier die Anwendung von umgangssprachlichen Elementen gezielt und bewußt ist. Die geschriebene Umgangssprache ist hauptsächlich (noch) stilistisch markierter Kode. ${ }^{<>>}$"Was sich verschiebt, ist also nicht primär das Gefüge der Existenzformen, sondern das Verhältnis von Sprechern zur Verwendung von Existenzformen" (HARTUNGSCHÖNFELD 1981: 92). Daraus lassen sich verschiedene kommunikative Funktionen der Umgangssprache ableiten.

In dieser kommunikativ geprägten Behandlungsweise ist die Möglichkeit fürs Überwinden der Schwierigkeiten beim Klären des Begriffs Umgangssprache zu suchen, der auch terminologisch nicht gelöst ist. Die ausschließliche Beachtung der systembezogenen Parameter führt nämlich nicht zu zufriedenstellenden Lösungen. 
Eine kommunikativ geprägte Definition der Umgangssprache würde somit lauten: "Die Umgangssprache ist eine vertikal differenzierte, variantenreiche Existenzform der deutschen Gegenwartssprache, die historisch als Ausgleichsprodukt zwischen den Dialekten und der Literatursprache entstanden ist und die vor allem mit ihrer literatursprachenahen überregionalen Schicht als gleichwertige Sprachvarietät in alle Funktionalstile eindringt und dort spezifische kommunikative Funktionen erfüllt".

Auch bei der Festlegung des normativen Charakters der Umgangssprache ist nur der systembezogene Horizont zu eng. Die Beachtung der situativ bedingten Normen der Umgangssprache ermöglicht erst recht ein komplexeres Begreifen des entstehenden sprachlichen Normsystems der Umgangssprache. Der Normbegriff streut auf einer Skala mit einer Toleranzbreite für Abweichungen, so daß hier nicht mit dem Begriff "Präskriptionen" (SPERLBAUM 1975: 10) operiert, sondern - die oben berührte Dynamik beachtend - vielmehr mit BETTEN von mehreren durch Redekonstellationen gesteuerten "Normniveaus" gesprochen wird (vgl. BETTEN 1985: 364). Diese "Normniveaus" bewegen sich im Spannungsfeld angemessen - nicht angemessen, zweckmäßig - nicht zweckmäßig. (Vgl. a. HARTUNG 1977: 16, HARTUNG-SCHÖNFELD 1981: 89.)

$\mathrm{Zu}$ unterscheiden ist zwischen der Umgangssprache als Existenzform der Nationalsprache und der Umgangssprache als Stilebene, herauszufinden sind aber auch die genaue Abgrenzung bzw. die Überschneidungsbereiche und Korrelationen zwischen der Umgangssprache einerseits und der Stilfärbung sowie der pejorativen, markierten und übertragenen Verwendung der Ausdrucksmittel andererseits.

Offen bleibt die Frage, ob Umgangssprache nur eine Übergangsphase in der Entwicklung der Sprache als System und als Verständigungsmittel ist und wie die künftige Entwicklung sein wird. Die stilistische Markiertheit der Umgangssprache in der Schriftsprache gewährleistet $z$. Z. noch ihren funktional bedingten Gebrauch.

\section{FAKTOREN UND BEDINGUNGEN DER KOMMUNIKATION}

Das Hauptanliegen der Dissertation war es, das Verhältnis zwischen dem System der Kommunikationsdeterminanten (Faktoren und Bedingungen der Kommunikation) einerseits und den sprachlichen Besonderheiten des Textes als Resultat der Textgestaltung andererseits aufzuzeigen, und zwar in beiden Richtungen, sowohl bei der Textgestaltung wie auch bei der Textrezeption.

Die Faktoren und Bedingungen der Kommunikation bilden den äußeren und den inneren kommunikativen Rahmen des Kommunikationsereignisses. Unter dem Begriff äußerer kommunikativer Rahmen der Kommunikation werden hier jene allgemeinen Charakteristiken der Zeitungen subsumiert, die mittelbar die sprachlichen Besonderheiten in diesen Zeitungen beeinflussen. (Vgl. zur Kommunikationsebene nullten Grades in der Mustertextanalyse.) Es handelt sich um folgende Parameter, die latent und auf ähnliche Weise die Texte einer Zeitung (sowie deren Sprache) prägen: Leitung des Zeitungshauses (Besitzer - staatlicher, gesellschaftlicher oder Privatbesitz, Verleger, Redaktion, Herausgeber) und ihre 
(politische) Orientierung, Verlagsort, Art des Erscheinens (Tagesblatt, Wochenblatt, Zeitung, die alle 2 Wochen erscheint, Monatsblatt usw.; Morgenblatt, Abendblatt u. ä. m.), Auflage, regionale Verbreitung (Lokalblatt, überregionale Zeitung) sprachliche Orientierung ((sprach)konservative - (sprach)innovative Zeitung), die behandelte Thematik (allgemeine, spezialisierte; Beilagen), die damit einhergehende Programmpolitik der Zeitung, typischer Adressat (disperses Publikum, Vermittleradressat, spezielles Publikum bezüglich des Fachs, der Bildungsstruktur, des Alters, des Geschlechts u.a.). Den inneren Kommunikationsrahmen des Kommunikationsereignisses sehe ich - auch in Anlehnung an "Funktional-kommunikative Sprachbeschreibung" (SCHMIDT et al. 1981: 18, 20, 203) und an "Sprache - Bildung und Erziehung" (SCHMIDT et al. 1977: 170) (vgl. auch SANDIG 1986: 29, 35) - in den fünf wesentlichen Determinantenkomplexen jeder kommunikativen Handlung, die voneinander hierarchisch abhängig sind, so daß ihre Komponenten gewissermaßen beliebig, jedoch in Einklang mit gewissen Gesetzmäßigkeiten kombiniert werden, in dem

1. kausalen Determinantenkomplex,

2. intentionalen Determinantenkomplex $<10>$,

3. thematisch-gegenständlichen Determinantenkomplex ${ }^{<11>}$,

4. situativen Determinantenkomplex,

5. strategisch-operativen Determinantenkomplex.

$\mathrm{Zu}$ wissenschftlichen Zwecken ist zu bestimmen, welche Parameter dabei als relativ gegebene Konstante (mit mehr objektivem Charakter) gelten (können), welche jedoch zu den mehr subjektiv geprägten Variablen gehören.

Dabei ist gesondert dem Umstand Rechnung zu tragen, daß zu dem strategischen Aspekt der Textgestaltung nicht nur der strategisch-operative Determinantenkomplex (Wahl der Mittel und Operationen zur Durchführung eines Kommunikationsprozesses - Kommunikationsplan, Textaufbau, d. i. Architektonik und Komposition, Kommunikationsverfahren (KV), funktional-kommunikative Merkmale (FKM), Textsorte) gehört, sondern i.w. S. auch andere Determinantenkomplexe, vor allem der thematisch-gegenständliche (Wahl des Kommunikationsgegenstands) und der situative (Wahl der Realisationsweise, Zeit- und Ortswahl der Kommunikation, Wahl des Kommunikationspartners).

Besondere Aufmerksamkeit gilt in der Untersuchung den KV als Strukturelementen der Kommunikationspläne. Die Bestimmung eines KV wird hauptsächlich von der Kombination allgemeiner und spezieller FKM beeinflußt, die präkommunikative Wesensmerkmale von KV sind und als solche ein Bindeglied zwischen dem kommunikativen Überbau des Kommunikationsereignisses und der Art seiner konkreten Vertextung. 


\subsection{Der Mustertext}

Helga BAMMERT-SACHER: Die alte Dame ist ein Tramp. (Untertitel:) Ein Rosenstrohhut erweist sich als wichtiges Requisit (Die Zeit, Nr. 44 - 29. Oktober 1982; Sparte "Reise", S. 57 f.) Ein größeres Photo (dieses zeigt eine sportlich gekleidete - Kniebundhose, Rucksack, Rosenstrohhut - ältere Dame, die mit hochgerecktem Daumen - ein Symbol des Autostops - am Straßenrand wartet) im rechten oberen Winkel der Seite 57 trägt den Untertitel: "Helga Bammert-Sacher beim Start an der Autobahnauffahrt Hamburg" und ist begleitet von dem Kommentar: "Sie war Schauspielerin, ist 61 Jahre alt und gleichermaßen reise- und abenteuerlustig. Sie lebt in Hamburg und liebt Rom. Wie ein Teenager fuhr sie in die Ewige Stadt, mit Rucksack und hochgerecktem Daumen."

Es folgt eine stark verkürzte, auf einige tragende Sätze reduzierte Version des Mustertextes.

1. "Na, willste mit? 2. Ich fahr' bis Seesen." 3. Die Stimme kommt von oben, auf dem Rastplatz von Stillhorn. 4. Ich gucke hoch in ein gemütliches Gesicht, ein bißchen jünger als meines: 5."Danke, eigentlich wollte ich mit einem Pkw fahren." 6. Leichte Enttäuschung. 7. "Na, wie du willst." 8. Schlechtes Gewissen bei mir: 9. Warum sollte ich nicht mit einem Lastwagen starten. 10. Ich danke und klettere hoch mit Rucksack und Bündel. II. "Ich heiße Hermann, wie heißt du?" 12. "Was, Hermann? 13. So heißt mein zweiter Schwiegersohn." 14. Wir sind gleich vertraut.

15. Der Rundblick ist weit, ich bin zufrieden. 16. Die drei Kinder haben sich nicht aufgeregt über meinen Plan, nach Rom zu trampen, aber die Freunde. 17. Warnungen vor Vergewaltigung, Unfall, Raub. 18. Ich hatte Erfahrungen mit dem Trampen nach dem Krieg bis Anfang der fünfziger Jahre. 19. Allein, später mit meinem Mann von Bayern bis Flensburg ins Theater-Engagement, dann mit einem Kind, schließlich mit zweien. 20. Seither nehme ich selbst Anhalter mit.

21. Hermann will keinen Kaffee aus meiner Thermoskanne, er muß in Seesen schlafen. 22. Gerne nimmt er jemanden mit, da wird man nicht so müde. ... 25. In Seesen erlebe ich es und oft danach, den kleinen Schmerz, weil man sich trennt. 26. Drei Schritte vom Wagen weg und aus.

... 29. Ein junger Mann nimmt mich bis Kassel mit. 30. Er ist Landschaftsgärtner, will sich umschulen lassen, Krankengymnast werden. 3l. Er ist total genervt, weil das Baugewerbe die Gärtnerei einzementiert. 32. Was soll das, einen Baum durch allerlei Tricks zu bewässern und zu belüften, wenn man doch nur einfach genug Erde um ihn herum lassen kann?

... 38. Keine zehn Minuten später fährt ein Göttinger Kaufmann vor, ich werde mit einem feinen Auto zur "Documenta" gebracht. ...

40. Am Abend trinke ich zwei Äppelwoi bei Pedro, dem Spanier, und bestelle 
nur Brot dazu 41. Pedro will kein Geld für das Brot. 42. "Wo kommen wir denn da hin, wenn wir uns Brot bezahlen lassen?" ...

48. Am zweiten Morgen frage ich in der Herberge, ob jemand zur Stadt runterfährt. 49. Ein Kunsterzieher aus Braunschweig bringt mich bis zur Autobahn, unkt aber fürchterlich über die Schwierigkeiten, die ich in Italien haben würde.

57. Ich aale mich hinten und bin wieder ganz froh. 58. Dieser Wechsel der Stimmungen, ob du nun drinnen oder draußen bist! ...

... 75. Wir fahren über den Gotthard, und ich denke, ach, da kann doch die ganze "Documenta" nicht mit, dieses Licht über den Bergen, diese Farbigkeit auf dem Geröll. ... 82. Am Montag sind die Museen zu, ganz gut, denn Rom ist noch weit. ...

84. Da bin ich also in Rom, selig, und kann es gar nicht ausdrücken. ...

90. Das Wetter war, ist und bleibt einzig schön. 91. In der Villa Borghese kann ich mich nicht satt sehen an den Skulpturen Berninis, an der Madonna mit Kind von Giovanni Bellini. ...

... 98. Nach der ersten Woche bin ich wütend, weil ich nichts mehr aufnehmen kann. 99. Da erscheint zum Glück Ari. ...

... 112. Den besten Frascati gibt's bei unseren lieben Nonnen. ... 114. Ich muß wieder weg.

115. Diesmal habe ich vor, über den Brenner zu fahren, und es gelingt. 116. Der Bus durch Rom zur Autobahn fährt 45 Minuten. ... 118. Plötzlich ein Dutzend Polizeiautos, jetzt bist du dran, denke ich und spiele Vogel Strauß. 119. Vorbei, und keine Schimpfe! ...

124. Von Orvieto bis Florenz wieder mal ein Lastwagen, pieksauber. 125. Der Fahrer, um 40, sagt ziemlich sofort, daß er mit mir schlafen will. 126. Marito in paradiso würde ziemlich böse mit mir sein, wenn ich das täte, sage ich hilflos und albern. 127. Der Junge bleibt friedlich, sagt dann, er dürfe sowieso niemanden mitnehmen, tanken muß er auch, da kann ich raus. ... 131. Dann hält ein Geschäftsmann mit Kompagnon in Verona, und ich kann bis Bad Aibling mit ihm fahren. 132. Er ist korrekt und freundlich, aber es gibt keine Fraternisation. 133. Mitfahrer, halt's Maul. ...

... 138. Zwei Jungen aus Rosenheim halten an. ... 141. Es ist schwer, von Rosenheim wegzukommen. ... 143. Ich muß weit laufen, ehe mich jemand zur Auffahrt bringt. 144. Dann fahre ich nur 30 Kilometer mit einem jungen Geschäftsmann ...

... 148. Auf der Ausfahrt Richtung Nürnberg fühle ich mich mal wieder wie ausgesetzt, steige dankbar in einen Kleinbus um. 149. Dunst von Schweiß, Öl und Müdigkeit umfägt mich. 150. Nix Deutsch, nix sonstwas. 151. Gülan kommt aus der Heimat und fährt in die Niederlande zurück, auf dem Rücksitz liegen Brot, Sonnenblumenkerne, Äpfel. 152. Er gibt mir auch einen, wir reiben sie an unseren Hosen blank. 153. Gülan sagt: "Du gutt Frau, Hand warm." 154. Und macht mir mit zwei weiteren Worten klar, was er will. 155. Auf die Fensterscheibe male ich "61", das berührt ihn überhaupt nicht. 156. Gülan ist ein richtiges Mannsbild, Mordskerl. 157. 
Ich werde ganz stutzig: 158. Wäre hier nich alles rundherum schmutzig, sondern geschähe der "Antrag" in einem ästhetischen Ambiente, ich weiß ja nicht. 159. Gleichzeitig ist da aber der Gedanke "Bloß raus beim Tanken". 160. Ich gucke auf die Skala, er muß bald halten.

161. In Nürnberg-Feucht muß ich lange warten, bis Rudi mein Kopfputz gefällt: 162. "Datt is doch ein zu schönes Hütchen." 163. Rudi fährt einen Tanker mit einem giftigen Zeug, der Grundlage der Schaumstoffherstellung. 164. "Wenn wir umkippen, die Dämpfe sind ganz schön gefährlich." 165. Rudi zeigt mir Papiere, die das alles bestätigen. 166. Ich komm mir vor wie in "Lohn der Angst", das gruselt schön. 167. Rudi ist ganz ungefährlich, erzählt wie ein Wasserfall, vom Garten, von seinen Katzen, von Frau und Sohn, von der Briefmarkensammlung und daß die Schwester Rosinen im Kopf hat, weil die Tochter Jura studiert. ... 173. Da stoppt ein heller Junge, macht die Tür auf, ich sage mein Sprüchlein, habe Glück, die Richtung stimmt. 174. Er fährt mit einem Affenzahn und heißer Kassettenmusik 175. Ich denke, mein Kopf platzt, da hält er auch schon bei der Ausfahrt Groß-Gerau, jetzt ist es nur ein Klacks, geschafft. ... 177. Meine Tochter weiß nicht, daß ich drei Autos brauche, um an das erste Autobahnschild ranzukommen; soll sie auch nicht, ist mein Bier. 178. Im Gewirr der Auf- und Abfahrten um Frankfurt hält ein Taxi meinetwegen. 179. Ich bin platt, da hätte ich nie einen Versuch gemacht....

181. Schließlich komme ich bei Friedberg an die Lehrerin, die zu einer Tagung wegen Paketsendungen für Polen nach Minden muß. 182. Über die Kirche hat die 36jährige Mutter des sieben Monate alten Hendrik eine Riesenaktion aufgezogen, ihr Mann macht mit. ... 187. Ein junger Mann, Assistent an der Aachener Uni, ist froh, uns gefunden zu haben. ...

... 191. Meine Fahrerin kommt aus der Provence, die Ente ist voller Kräuter.

200. Ich darf die Anhalterei nicht hochjubeln. 20l. Zuviel Ungutes ist schließlich doch auf beiden Seiten passiert. 202. Es bleibt eine ganz persönliche Form der Reiserei. 203. Bei mir ist viel Show dabei. 204. Ach was, es gibt so viele Formen der Eitelkeit.

Im Text erzählt eine unternehmungslustige pensionierte Schauspielerin von ihren Erlebnissen auf ihrer Autostopreise von Hamburg nach Rom und zurück.

Es handelt sich um eine erlebnisbetonte Erzählung, die in 1. Person und im Präsens ausgewählte Ereignisse während eines ungewöhnlichen Unternehmens einer älteren Dame dynamisch darstellt.

\subsection{Die kommunikativen Determinanten des Mustertextes}

Ehe i.e.S. auf die Faktoren und Bedingungen der Kommunikation im Mustertext eingegangen wird, sollen einige Daten zur Zeitschrift "Die Zeit" angeführt werden, die den sog. "äußeren kommunikativen Rahmen" des Textes darstellen (vgl. 4.).

"Die Zeit" ist eine "Wochenzeitung für Politik, Wirtschaft, Handel und Kultur", die thematisch sehr aufgefächert ist, denn sie behandelt beinahe alle Bereiche der 
menschlichen Betätigung, wovon auch verschiedene Sparten und Beilagen zeugen. "Unter den wöchentlich erscheinenden 'Zeitungen' (75 Titel 1975) verdient 'Die Zeit' (Aufl. 3/1979: 432 700; über 1,1 Mill. Leser) besonderer Erwähnung" (NAIL 1985: 1664). Es geht also um eine überregionale Zeitschrift (vgl. NELLEN 1986: 103), die in ihr verwendete Sprache ist ein für den gesamten deutschsprachigen Raum verbindlicher Kode, wodurch die These von der regionalen Gebundenheit der darin enthaltenen umgangssprachlichen Elemente in Frage gestellt wird (vgl. u.a. LANGNER 1986: 104), denn "/e/ine überregionale Zeitung verwendet andere Sprachmuster als die kleine Lokalzeitung" (NELLEN ibid.).

Es gilt nun, die unter 4. übersichtlich angeführten Begriffe in bezug auf unseren Text zu untersuchen. Eingangs ist festzustellen, daß Reiseberichte (Reiseerzählungen), wenn auch in Form kürzerer Zeitschriftentexte, weitestgehend Elemente "unnützen" künstlerischen Schaffens aufweisen und somit nur bedingt zu den Textsorten gezählt werden können, deren Produzenten, einer konkret gesetzten Kommunikationsaufgabe folgend, kommunizieren (wie etwa im Kommunikationsbereich bzw. funktionalen Stiltyp der Sachprosa - des Amts- und Verwaltungsverkehrs, der Politik, Bildung, Wissenschaft u.a.m.). Die Erzählerin scheint in unserem Fall vielmehr durch einen inneren (emotionalen, instinktiven) Drang dazu motiviert gewesen zu sein, ihre außergewöhnlichen Erlebnisse (eine pensionierte Frau reist üblicherweise doch nicht per Anhalter durch Europa!) an andere weiterzugeben, um dadurch vielleicht sich selbst von eventuellen Bedenken zu befreien. Erst sekundär könnte man auch von einer konkreten Absicht, somit vom Ziel dieser kommunikativen Handlung, verbunden mit einem eventuellen "Auftraggeber" (Zeitschriftenredaktion ?), sprechen. Dieses Ziel - das sei erst einmal intuitiv vermutet - mag darin liegen, mit ihren Erlebnissen andere Menschen zu informieren, zu belehren, zu erheitern und zu unterhalten und zugleich zu zeigen zu versuchen, daß auch die nicht der gesellschaftlichen Norm entsprechenden Handlungen nicht gleich zu verurteilen sein müssen, daß auch anständige, ehrliche, betagte Menschen Abenteuer erleben und an Außergewöhnlichem teilnehmen wollen. (Ansätze zu weiterführender Bestimmung der direkten und indirekten kommunikativen Funktion des Textes - siehe unten.)

Das Rahmenthema ist durch die Sparte "Reise" (Unterhaltung!) und den Titel des Textes gegeben. Ein spezielles explizites Thema ließe sich - analog der Kommunikationsaufgabe und der Kommunikationsabsicht - nur schwerlich als gegeben ansetzen, weil ein Thema zu sehr mit einer deutlichen intentionalen Komponente einhergeht, deren der vorliegende Text jedoch entbehrt. ${ }^{<11>}$

Interessanter ist, bezogen auf unseren Untersuchungstext, der situative Determinantenkomplex, und zwar wegen der Dichotomie, die im Text infolge der Doppelkommunikationssituation, einer Art Phasenverschiebung, entsteht. Diese "Dichotomie" bezieht sich auf alle Parameter einer kommunikativen Originalsituation und einer durch Textkonserve entstandenen kommunikativen sekundären Situation (vgl. DIMTER 1981: 43): auf Ort, Zeit, Medium, Kanal, Partnerbezichungen, Kommunikationsbereich. Die Originalsituation ist die authentische Situation, die die Erzählerin auf ihrer Reise erlebt hat: Hamburg - Rom - Hamburg (als Ort der Reise), 
Sommer 1982 (als vermutlicher Zeitpunkt der Reise), direkter (mündlicher) Kontakt mit den Kommunikationspartnern - den Fahrern und anderen Tramps (als Medium fungiert also die gesprochene Sprache, abgesehen von unmittelbaren Notizen in einem eventuellen provisorischen Tagebuch), Kommunikationsbereich der Alltagskommunikation auf der Reise. Auf der anderen Seite ist die sekundäre Kommunikationssituation durch eine Distanzierung von dem unmittelbar Erlebten auf der Reise gekennzeichnet. Die Erzählerin - Autorin legt ihre Erinnerungen an die aufregende Reise fest, indem sie sie, die authentische primäre Situation simulierend, möglichst getreu wiederzugeben versucht. Dennoch befindet sich die Erzählerin zu einem späteren Zeitpunkt an einem anderen Ort, sie bedient sich eines anderen Mediums (geschriebene Sprache)(vgl. Anm. ${ }^{<6>}$ ), sie muß damit rechnen, daß von ihr Geschriebenes von unbekannter Leserschaft (disperses Publikum) gelesen werden wird (Kommunikationsbereich Presse und Publizistik). In Opposition stehen also die Kodierungsbedingungen sprechsprachlichen Gestaltens (Situationsentlastung, Redundanz, Spontaneität, Auslassungen) und schreibsprachlichen Gestaltens (Distanzierung und damit einhergehende gründlich durchdachte Entscheidungen infolge unbegrenzter Überlegungsmöglichkeiten (vgl. SCHMIDT et al. 1977: 70). Von besonderer heuristischer Bedeutung ist diese Feststellung füreine Untersuchung umgangssprachlicher Ausdrucksmittel. Es handelt sich nämlich in unserem Text nicht allein um eine spontane, unkontrollierte, unbewußte Verwendung von umgangssprachlichen Ausdrucksmitteln in primärer kommunikativer Situation, diese umgangssprachlichen Ausdrucksmittel werden vielmehr in Modifikationen der sekundären kommunikativen Situation bewußt durchfiltert. Der vorwiegend bewußte Einsatz umgangssprachlicher Ausdrucksmittel legt allerdings die Voraussetzung nahe, daß kommunikative Funktionen dieser umgangssprachlichen Ausdrucksmittel mehr oder weniger gefestigt, konventionalisiert sind. So eignen sich umgangssprachliche Ausdrucksmittel ganz besonders zur Bestimmung und Analyse ihrer kommunikativen Funktionen, was ein Hauptanliegen dieser Arbeit ist.

Im Rahmen des strategisch-operativen Determinantenkomplexes sollen für diesen Mustertext der Textaufbau und der Kommunikationsplan mit seinen Strukturelementen (den KV) näher erläutert werden.

Bevor dann einige Belege der Mustertextanalyse (aus Platzmangel nur in sehr reduziertem Umfang und nur) exemplarisch dargestellt werden, setze ich mich - um das Verständnis und die Lesbarkeit der sprachlichen Analyse zu erleichtern - mit den Begriffen Kommunikationsebene und Rededarstellungsform sowie mit der Opposition Handlungsebene der Erzählung vs. Situationsebene der Erzählung auseinander.

Auch das knapp skizzierte System der kommunikativen Funktionen des Mustertextes und ein Versuch seiner Textsortenbestimmung sollen als Hilfsmittel für die Durchführung einer komplexen Sprachanalyse des Mustertextes betrachtet werden.

Der Textaufbau umfaßt die äußere (formale) Gliederung des Textes in Absätze und Sätze, d. h. seine Architektonik, sowie die innere (inhaltliche) Gliederung in gedankliche Einheiten, d.h. seine Komposition (vgl. SCHMIDT et al. 1977: 70). Zwischen den beiden Gliederungsprinzipien bestehen weitgehende Übereinstimmungen 
und Korrelationen, es sind jedoch auch Abweichungen möglich, die nicht unbedingt auf eine Inkompetenz des Textproduzenten zurückgehen müssen, sondern im Gegenteil Ausdruck einer bewußten und gekonnten Strategie sein können.

Architektonisch zerfällt der Text in XXI Absätze mit insgesamt 204 Sätzen. ${ }^{<12>}$ heiten:

Eine grobe kompositorische Gliederung ergibt im Text zuerst vier größere Ein-

A: Der Weg nach Rom (1-83),

B: Der Aufenthalt in Rom (84-114),

C: Die Rückreise (115-199),

D: Der Abschluß (200-204).

Diese Grobgliederung zerfällt weiterhin in kleinere, vor allem zeitlich und lokal bedingte strukturelle Einheiten. "Ein Erzähltext ist in seinem Voranschreiten an der Zeitachse ausgerichtet. Eine temporale Qualifikation der Sätze ist deshalb quasi obligatorisch, der Informationswert kann mithin sehr gering sein" (EROMS 1986: 17). (Vgl. auch zur Textsorte (Reise)Erzählung hier unten)

A1: Hamburg - Kassel (erster Tag) (I, 1-39)

$\mathrm{A}_{1,1}$ : Kontakt mit dem 1. Fahrer (I, 1-14) $<13>$

A1,2: Rückblende ${ }^{<14>}$ (II, 15-20)

A1,3: Noch die Fahrt mit dem 1. Fahrer (III, 21-26)

A1,4: Raststelle - Fahrt mit dem Gärtner (IV, 27-32)

A1,5: In Kassel, Fahrt mit dem 3. Fahrer (V, 33-39)

A2: Übernachtung in Kassel (VI, 40-47)

In der Jugendherberge

A3: Kassel - Basel (zweiter Tag) (VII, VIII, 48-72)

A3,1: Von der Jugendherberge bis zur Autobahn (VII, 48-56)

A3,2: Mit dem BMW-Fahrer und seiner Freundin bis Basel (VIII, 57-72)

A4: Basel - Rom (IX, 73-83)

A4,1: Mit dem Schweizer Ehepaar bis Florenz (IX, 73-80)

A4,2: In Florenz (IX, 81-83)

B1: Erster Eindruck von Rom $(X, 84-89)$

B2: Besichtigung Roms (XI, 90-92; XII, 93-108; XIII, 109-114)

C1: Abgang von Rom, Rom-Orvieto (XIV,115-123)

Bus, Polizei, Transportwagen, junge Römerin 
C2: Orvieto - Florenz - Toscana - Verona - Bozen - Bad

Aibling - Rosenheim (XV, XVI, 124-146)

$\mathrm{C}_{2,1}$ : Lastwagen (XV, 124-127)

$\mathrm{C}_{2,2}$ : mit zwei Neapolitanern unterwegs (XV, 128-131)

$\mathrm{C}_{2,3}$ : Geschäftsmann mit Kompagnon (XV, 132-136)

$\mathrm{C}_{2,4}$ : zwei Jungen (XVI, 137-142)

$\mathrm{C}_{2,5}$ : "jemand" (XVI, 143)

$\mathrm{C}_{2,6}$ : junger Geschäftsmann (XVI, 144-146)

C3: Rosenheim - Nümberg (XVII, 147-160)

C4: Nürnberg - gen Norden (XVII, 161-171)

Tankerfahrer

C5: bis Großgerau (XVII, 172-175)

ein heller Junge

C6: Umgebung von Frankfurt (XVII, 176-180)

bei der ältesten Tochter

C7: Friedberg - Osnabrück (XIX, 181-184)

Lehrerin

C8: Raststätte (XIX, 185-189)

andere Reisende

C9: Sittensen - Hamburg (XX, 190-199)

Französischlehrerin

$D$ : (einteiliger) Schlu $\beta$ (XXI, 200-204)

Bei der Bestimmung des Kommunikationsplans eines umfangreicheren Textes muß damit gerechnet werden, daß der Gesamtplan, der der dominanten Kommunikationsabsicht im Text entspricht und nach ihr benannt wird (vgl. SCHMIDT et al. 1977: 148 und SCHMIDT et al. 1981: 28) und der mit der Gesamtzielsetzung der Sprechhandlung übereinstimmt (vgl. DIMTER 1981: 65), mehrere untergeordnete Teilpläne (instrumentale Ziele der Sprechhandlung - vgl. a.a.O.) enthält.

Eine wichtige Tatsache in diesem Zusammenhang ist, daß bei den Kommunikationsplänen (wie auch bei ihren Strukturelementen - den KV) keine strengen Abgrenzungsmöglichkeiten vorhanden sind, sondern daß dabei (vielmehr) das (offene) Prinzip der Dominanz, gegenseitiger Beeinflussungen und Übergänge zum Ausdruck kommt. Eine kommunikative Absicht kann also nicht nur durch einen einzigen Kommunikationsplan realisiert werden, sondern es gibt mehrere Varianten 
(vgl. SCHMIDT et al. 1981: 28), wobei es unter dem strategischen Gesichtspunkt vor allem auf die Kombination der einzelnen Teilpläne, auf die Abfolge der Teiltexte ankommt (vgl. GÜLICH-HEGER-RAIBLE 1979: 80). Der Gesamtplan ist eine Resultante der Teilpläne, dessen Bestimmung hängt mit der Forderung nach "semantische/r/, kommunikative/r/ und strukturelle/r/ Ganzheitlichkeit des Textes" zusammen (MOSKALSKAJA 1984: 19, 23, 27). Dem Gesamtplan entspricht auch ein dominantes KV.

In unserem Mustertext ist der Gesamtplan erlebnisbetontes Informieren, mit dem das dominante KV Erzählen einhergeht. "Beim erlebnisbetonten Informieren verfolgt der S/S (Sprecher/Schreiber, S. B.) das Ziel, dem H/L (Hörer/Leser, S. B.) seine Empfindungen, Eindrücke und Einstellungen von bzw: zu bestimmten Sachverhalten zur Kenntnis zu geben. Deshalb ist die Darstellung nicht in erster Linie von dem Bestreben bestimmt, die Sachverhaltsstruktur adäquat wiederzugeben, sondern stärker von subjektiven Aspekten" (SCHMIDT et al. 1981: 24). "Erzählen ist das subjektiv bestimmte, erlebnisbetonte, anschauliche sprachliche Darstellen eines einmaligen bzw. als einmalig aufgefaßten realen oder fiktiven Geschehens. Die Elemente des Geschehens werden so angeordnet, daß Spannung entsteht" (SCHMIDT et al. 1977: 159). (Vgl. auch die folgenden Ausführungen zur Textsorte des Mustertextes.)

Die Teilpläne des Mustertextes wären:

DAS AKTIVIEREN, u. zw. Interessieren (Sätze 1-14) mit entsprechenden KV Anregen, Aufrufen, Fragen.

DAS KLÄREN (Satze 15-20), das m. E. z. T. auch Informieren, aber auch Aktivieren (Überzeugen) involviert, bzw. in diese übergeht (vgl. SCHMIDT et al. 1981: 27). Entsprechende KV sind Mitteilen, aber auch Begründen, Rechtfertigen, Zurückweisen, Explizieren, Entschuldigen, Befürworten, Antworten, Widerlegen, Feststellen.

DAS INFORMIEREN, u. zW. erlebnisbetontes Informieren als dominanter Teilkommunikationsplan (Sätze 21-199) mit den KV Erzählen, Schildern, Mitteilen, Beschreiben, Feststellen, Behaupten.

DAS KLÄREN (Sätze 200-204), das mit Elementen emotionalen Bewegens durchsetzt ist (vgl. SCHMIDT et al. 1981: 27) und folgende KV enthält: grundlegend ist in den 5 Sätzen das Beurteilen (vgl. SCHMIDT et al. 1981: 161, 163) als konstitutives KV über den folgenden elementaren (integrierten) KV: Feststellen (200), explizierendes Begründen (201), Definieren (202), Explizieren (203), Verallgemeinern (204).

In Sätzen 1-14 sehe ich einen aktivierenden Teilplan wegen der erkennbaren (evidenten) "Intention, den Textrezipienten in einer bestimmten Weise zu beeinflussen ..." (SCHMIDT et al. 1981: 24), und zwar im Sinne von Interessieren, das die Aufmerksamkeit des Lesers auf den Textinhalt lenken soll (vgl. SCHMIDT et al. 1981: 26). Es ist ein Informationsgefälle zwischen Erzähler und Leser vorhanden, denn die Erzählung setzt mitten im Geschehen ohne Einleitung ein und läßt durch die damit verbundenen Teilinformationen die Spannung entstehen. $\langle 15\rangle$. Auch nachgestellte 
metakommunikative redekennzeichnende Sätze (Satz 3) sind ein Indiz dafür (vgl. mehr dazu bei GÜLICH-HEGER-RAIBLE 1979: 82, 87, 102).

In Sätzen 15-20 haben wir den Kommunikationsplan Klären, weil "in dem Beziehungsgefüge Textproduzent - Textrezipient - Kommunikationsgegenstand der Kommunikationsgegenstand akzentuiert ist" (SCHMIDT et al. 1981: 26). Es geht hier um eine Art Rückblende, Retardation, die als eine aus dem übrigen Text herausragende objektive Koordinatensetzung der Situation das ungewöhnliche Unterfangen zu begründen, zu rechfertigen, zu entschuldigen, zu befürworten versucht, indem sie die in anderen potentiell auftauchenden Bedenken, Befürchtungen, Warnungen zurückweist und auf sie z. T. widerlegend antwortet. Dem oben erwähnten dynamischen Prinzip der Kombinationen von Teilplänen (und KV) zufolge wären hier Sätze 15-17 als dem Klären untergeordnetes Informieren aufzufassen, die weiteren 18-20 jedoch als Aktivieren (Überzeugen; Widerlegen). Die Erzählende verfolgt hier auch die Absicht, durch die Darlegung und Klärung des Problems auf ihre Kommunikationspartner einzuwirken (vgl. SCHMIDT et al. 1981: 27), sie durch objektive Beweise zum positiven Bewerten ihrer (auf den ersten Blick ausgefallenen) Absicht zu bringen (vgl. a.a.O.: 25).

In Sätzen 21-199 wird eindeutig der Teilkommunikationsplan erlebnisbetontes Informieren realisiert, der auch den Gesamtplan der Erzählung prägt.

In Sätzen 200-204 haben wir ein zweites Klären. Hier geht es seitens der Erzählerin um ein emotional gefärbtes selbstkritisches und stellungnehmendes Bilanzieren dessen, was sie erlebt hat. Wiederum steht nicht die Relation Erzähler Rezipient im Vordergrund, sondern die Gegenstandsproblematik selbst (das Trampen, insbesondere das Trampen einer 65jährigen Frau). Jedoch haftet auch dem Klären in diesem Absatz eine Art Aktivieren, spezieller, emotionales Bewegen an (vgl. SCHMIDT et al. 1981: 27). Primär ist dabei das Erkenntnisziel der Erzählerin (das Trampen sei "Anhalterei", "Reiserei", "Show", "Eitelkeit") $<16>$, und sie will damit den Leser gewissermaßen emotional bewegen, rühren, engagiéren, beunruhigen, was auch mit der Auffassung SCHMIDTs übereinstimmt, das emotionale Bewegen sei meist einer anderen Kommunikationsabsicht untergeordnet, insbesondere dem Mobilisieren, dem Überzeugen, dem erlebnisbetonten Informieren (SCHMIDT et al. 1981: 26).

Aufgrund der obigen Analyse ließen sich in unserem Mustertext drei die Spannung im Text steigernden Spannungsbögen feststellen (vgl. zur Textsorte hier unten). $<17>$

Der erste Spannungsbogen existiert einerseits zwischen dem aktivierenden Charakter der beiden ersten Teilpläne (das Aktivieren (I) und das Klären (II) könnten zusammen als ein aktivierender Teilplan höheren Grades aufgefaßt werden, der den Leser dazu anregen soll, mit der Textlektüre fortzusetzen) und andererseits dem darauf folgenden erlebnisbetonten Informieren, das den Leitgedanken des ganzen Textes determiniert.

Das zweite Spannungsgefüge erfolgt über die Grenzen einzelner Teilpläne hin- 
weg zwischen einerseits den am Textbeginn plazierten Ankündigungen (Vorahnungen) der Probleme und den Warnungen davor (explizit beschrieben in Sätzen 17, 49, implizit weist darauf die gesamte 1. Texthälfte bis Rom, d. h. die Kompositionseinheit A hin) und andererseits den in Wirklichkeit erlebten Unannehmlichkeiten auf der Rückreise (explizit in Sätzen 118, 125-127, 148-160, 163-166, 174, 175).

Der dritte Spannungsbogen in unserem Mustertext, der ebenfalls die kommunikative Spannung im Text steigert, besteht zwischen den beiden klärenden Kommunikationsplänen, die als zwei metaerzählende Kompositionseinheiten aus dem übrigen Text plastisch herausragen. Wenn das Klären in der Einstiegsphase (Sätze 15-20) als ein sachlich ausgerichtetes Präludium mit einer kataphorischen Signemfunktion (Teiltextfunktion) aufzufassen ist (vgl. DIMTER 1981: 24,BRINKER 1983: 136, GÜLICH-HEGER-RAIBLE 1979: 13 sowie BEAUGRANDE-DRESSLER 1981: 23), so ist das zweite, am Textende stehende Klären ein Postludium, das mit einem emotional gefärbten Anhauch die gesamte Odyssee als eine Art "Eitelkeit" abstempelt. Die beiden klärenden Textteile sind als persönliche Stellungnahmen der Erzählerin wie zwei Säulen (die eine mehr objektive, die andere mehr subjektive), zwischen denen das Gesamtgeschehen der Erzählung gespannt ist.

So wie die Kommunikationspläne hierarchische Abhängigkeitsrelationen aufweisen, so sind auch die Kommunikationsverfahren (KV) miteinander unterschiedlich (fast ohne Einschränkungen) kombinierbar. ${ }^{<18>}$ Man unterscheidet drei Klassifikationsmöglichkeiten der KV: unter dem Handlungsaspekt können die KV den Handlungs-, aber auch den elementaren Operationscharakter besitzen (vgl. HARNISCH 1983: 41 ff.), unter dem strukturellen Aspekt sind KV einfach und komplex (aus mehreren einfachen KV zusammengesetzt) (vgl. SCHMIDT et al. 1977: 155 f., 163, 167). KV können - hierarchisch gesehen - auf das Handlungsziel bezogene Gesamtverfahren sein (z. B. Erzählen), sie können aber auch konstitutive Verfahren sein (z.B. Schildern, das dem Erzählen unter- und dem Mitteilen übergeordnet ist) und/oder elementare (integrierte) KV (z.B. Mitteilen), die auf kommunikative Teilziele bezogen sind. (Vgl. HEUSINGER 1984: 162, SCHMIDT et al. 1981: 38, HARNISCH 1983: 44 sowie SANDIG 1986: 114, 321).

Über diese bekannten Tatsachen über die KV hinaus ist aufgrund der vorliegenden Untersuchung auf weitere Besonderheiten aufmerksam zu machen. KV könnten auch nach einem vierten, nach dem funktionalen Kriterium in formale und in tatsächliche KV eingeteilt werden. Das bedeutet, daß ein KV - ob Operations- oder Handlungstyp - für den Rezipienten u. U. eine von der usrprünglichen abweichende, eine modifizierte Zweckbestimmtheit aufweisen kann. So wird z. B. durch das KV Fragen primär ein kognitives Herantasten an das Unbekannte, ein Suchen nach Erkenntnis hervorgebracht (vgl. HARNISCH 1983: 49 sowie SCHMIDT et al. 1981: 81). Über diese primäre, bisweilen lediglich formale Handlung hinaus kann das Fragen auch weitere, sowohl inzitative als auch inventive Handlungskomponenten realisieren (vgl. ibid. sowie SCHMIDT et al. 1981: 83). ${ }^{<20>}$ Dabei ist am häufigsten die Perspektive Textproduzent - Figur - Andressat maßgeblich, zu unterscheiden sind aber auch Fälle auf derselben Kommunikationsebene von jenen auf verschiedenen Kommunikationsebenen (s. unten). Auf FKM der KV wirken bisweilen sekundär 
auch die Besonderheiten der auf hierarchischen Verhältnissen unter den KV beruhenden Klassifikation der KV ein. Das KV Mitteilen muß nicht unbedingt 'sachbetont' bzw. 'sachgemäß' sein (vgl. SCHMIDT et al. 1981: 35, 208). Innerhalb komplexer erlebnisbetonter KV wie z. B. Erzählen, kann das Mitteilen als elementares (integriertes) KV auch das FKM 'erlebnisbetont' aufweisen (vgl. HEUSINGER 1984: Anhang: 46). Generell läßt es sich vermerken, daß integrierte KV über ihren Rahmen hinaus solche FKM signalisieren können, die ihnen selbst nicht anhaften, die jedoch auch aus der vertikalen Interaktion mit den konstitutiven KV und dem (komplexen) Gesamtverfahren bisweilen auch auf der elementarsten Ebene (nachträglich) zum Ausdruck kommen. Auch sprachliche Elemente, mit denen das Mitteilen ausgedrückt wird (z. B. umgangssprachliche oder normalsprachliche), sind ein Kriterium, das über den vorwiegend sachbetonten oder erlebnishaften Charakter des Mitteilens entscheiden. (Vgl. auch SCHMIDT et al. 1981: 37, 227 f.).

Die Bestimmung der KV hängt auch von anderen Faktoren ab, z. B. vom Tempusgebrauch im Text ${ }^{<21>}$ und von der topologischen Lage des KV im Text. ${ }^{<2>}$

In der Mustertextanalyse wurde ein neues KV ermittelt, d.i. das Interjektieren oder emotionales Erleichtern (Sich-Entladen), das neben den bereits bekannten Gruppen von KV eine neue, vierte Gruppe von KV eröffnet, die weder deskriptiv noch inzitativ noch inventiv sind (vgl. SCHMIDT et al. 1981: 35 f. und HARNISCH 1983 :47). ${ }^{<2>}$ Neu scheint auch die Erkenntnis, daß einfache KV nicht unbedingt elementar sein müssen. So kann z. B. das Mitteilen auch als konstitutives KV fungieren, das also (funktional) anderen $\mathrm{KV}$ übergeordnet ist, die strukturell komplizierter aufgebaut sind (vgl. Sätze 22, 82).

Die Rededarstellungsformen sind ein bedeutendes Ausdrucksmittel, das die Bildhaftigkeit und die Ausdruckskraft im Text steigert und somit teilweise auch den Einsatz der Ausdrucksmittel lenkt, auch der umgangssprachlichen. Die Auseinanderhaltung der Rededarstellungsformen schärft unter Beachtung der Kommunikationsebenen zusätzlich das Gefühl für die Wohlkomponiertheit des Textes und für die Unterscheidung der Perspektiven des Autors, des Erzählers, der Figur(en) und des Adressaten.

Zum besseren Verständnis der verschiedensten Rededarstellungsformen (vgl. FLEISCHER-MICHEL 1977: 209) dient eine detaillierte Analyse der Kommunikationsebenen im Text. Sowohl ein herausgearbeitetes System der Rededarstellungsformen als auch ein diesem zugrunde liegendes Netz der Kommunikationsebenen haben sich in der Textanalyse als relevant für die Bestimmung der kommunikativen Funktionen gezeigt.

Mit Kommunikationsebene meine ich hier konkret die Art der Beziehung zwischen dem Sender und dem Adressaten, d. h. zwischen den Kommunikationspartnern im Text. Diese Beziehungen können mannigfaltig sein, weil der Sender i. w. S. nicht eine einzige Person ist, weil man verschiedene Typen von Adressaten unterscheiden kann und infolge dessen auch die Beziehungen unter ihnen direkt und indirekt sein können. Die Erkenntnis ist unbestritten, daß der endgültige, der tatsächliche Adressat eines in einem Text schriftlich fixierten Kommunikationsereignisses immer der 
Leser ist, auch in dem Fall, daß es innerhalb des Textes zu einer Art Vermittleradressaten kommen kann. Aus der Beziehung zwischen Sender und Adressat ergeben sich grundsätzlich zwei Ebenen der Kommunikation: die Metaebene und die sprachliche Ebene.

Die Metaebene oder die Kommunikationsebene nullten Grades meint dabei den nichtsprachlichen indirekten Kontakt einerseits zwischen denjenigen, die (als Sender) hinter einer Zeitung stehen (ich beschränke mich hier - wie bereits erwähnt - auf Zeitungstexte), und andererseits dem Zeitungsleser (als Adressat) (vgl. zum äußeren kommunikativen Rahmen in 4.).

Die sprachliche Kommunikationsebene i. w. S. - der Kontakt zwischen Sender und Empfänger erfolgt hier mit Hilfe sprachlicher Ausdrucksmittel - zerfällt in 3 weitere untergeordnete Kommunikationsebenen: ersten, zweiten und dritten Grades.

Die Kommunikationsebene ersten Grades besteht zwischen der Redaktion einer Zeitung und der Leserschaft, aber auch zwischen dem Autor (wenn er nicht mit dem Erzähler identisch ist) und der Leserschaft. Der Redakteur (der Zeitung) und u. U. der Autor des Textes tragen gelegentlich einleitende sprachliche Elemente zum Text bei, wodurch sie sich über den Rahmen des Textes hinweg direkt an den Leser wenden können. Dazu können gehören der Titel (häufig mit dem Thema des Textes identisch, das mit Intentionen einer Redaktion übereinstimmen sollte), ein oder mehrere Untertitel, Übertitel und/oder Zwischentitel, verschiedene Geleitworte und Einführungskommentare, aber auch das Bildmaterial und Illustrationen sowie die dazugehörigen Kommentare (s. den Mustertext).

Auf der zweiten Kommunikationsebene läuft der direkte Kontakt zwischen dem Erzähler (und zugleich Autor, wenn sie identisch sind) einerseits und dem Leser als Adressaten andererseits. Einen solchen Typ der Kommunikationsebene haben wir z. B. in Sätzen 15-20, 24-29, 37-40, u.a.m. Hauptsächlich objektiviert sich die Kommunikation in einer Erzählung auf dieser Ebene.

Die Rededarstellungsformen auf dieser Kommunikationsebene sind die Erzählerrede, die abstrahierte Rede, die erlebte Reflexion und die erlebte Rede sowie die indirekte Rede. (Vgl. FLEISCHER-MICHEL 1977: 209 f.)

Die Kommunikationsebene dritten Grades bedeutet, daß die Kommunikation zwischen Sender und (End)adressat (dem Leser eines Zeitungstextes) typischerweise über einen Vermittler verläuft. Dieser Vermittler ist durch eine Figur oder mehrere Figuren aus dem Text vertreten, die in unterschiedlichen Kombinationen miteinander und auch mit dem Erzähler kommunizieren, wenn dieser die Rolle einer am Geschehen beteiligten Figur übernommen hat. Auf diese Art und Weise kommt es zu einer anderen, zur sog. primären kommunikativen Situation (vgl. DIMTER 1981: 42), an der der Leser nicht unmittelbar beteiligt werden kann, obwohl diese primäre Sprechsituation von dem Erzähler (Textautor) nachträglich schriftlich fixiert worden ist, eben zu dem Zweck, mit möglichst getreuer Nachahmung des wirklich Erlebten auf den Leser möglichst überzeugend zu wirken.

Auf der Kommunikationsebene dritten Grades hätten wir zwei Rededarstel- 
lungsformen, und zwar die direkte Rede und den inneren Monolog. (Vgl. FLEISCHER-MICHEL 1977: a.a.O.)

Diese mehrdimensionellen Beziehungen verdienen besondere Aufmerksamkeit unter dem Blickwinkel der Kodierungsbedingungen: die primäre kommunikative Situation - spontane Dialoge in der Alltagssprache - wird von dem Erzähler (hier zugleich Autor) schriftlich niedergelegt, so daß sich die Kodierungskriterien einer mündlich erlebten Kommunikationssituation an den Kriterien der schriftlichen Kommunikation brechen (vgl. oben). So steht dem Autor ein praktisch unbegrenztes Inventar an Ausdrucksvarianten zur Verfügung, von der getreuen Wiedergabe der Primärsituation über teilweise modifizierende Eingriffe in diese spontane Formulierungsweise bis hin zur völligen Anpassung an die Forderungen des schriftlichen Verkehrs.

$\mathrm{Da}$ ß sich vor diesem Hintergrund $u$. a. auch verschiedene Rededarstellungsformen als ein sehr geeignetes Ausdrucksmittel anbieten, das dem Textproduzenten fein kombinierte Nuancenunterschiede fast unbegrenzt schaffen läßt, steht außer Zweifel. Gute Kenntnis der Charakteristiken verschiedener Rededarstellungsformen ist somit sowohl im Textgestaltungs- wie auch im -rezeptionsprozeß unabdingbar. Um die Problematik zu erneuern, werden hier die Charakteristiken einer Rededarstellungsform angegeben, die sich auf Grund der Mustertextanalyse als neu identifizieren ließ, und mit einigen wesentlichen Merkmalen der anderen in dem Mustertext verwendeten Rededarstellungsformen tabellarisch verglichen.

Figurenbeeinflußte Erzählerrede.

Die Bestimmung des Rededarstellungstyps scheint problematisch z. B. in Sätzen $21,22,30,31$. Sie lassen sich in keinem der bekannten Rededarstellungstypen einordnen. (Vgl. FLEISCHER-MICHEL 1977: a.a.O.) Es handelt sich höchstwahrscheinlich um eine besondere Unterart der Erzählerrede, die sich von der üblichen Erzählerrede dadurch unterscheidet, daß sie von der Figurenrede beeinflußt wird: der Erzähler spricht von dem, was er im Kontakt mit einer Figur von dieser Figur erfahren hat, so daß diese, sich neu abzeichnende Rededarstellungsart im Prinzip auf einen rekonstruierbaren Dialog mit der Figur, u. U. sogar auf die Figurenrede selbst zurückführbar ist, ohne daß diese verkürzt oder anders abstrahiert werden muß. Über das eventuelle Erscheinen einer (neuen) Figur im Text berichtet also die Erzählerrede (z. B. Satz 29), über das, was aus dem sprachlichen Kontakt und dem Informationsaustausch mit der Figur herauskommt, dagegen die sog. figurenbeeinflußte Erzählerrede (vgl. Sätze 30-31; vgl. auch MOSKALSKAJA 1984: 125-127). $<24>$

Diese Distinktion scheint im Rahmen dieser Untersuchung von Bedeutung, weil gewisse sprachliche Elemente aus der so entstandenen Erzählerrede eigentlich auf die ursprüngliche Figurenrede zurückgehen, wobei die Intensität der Beeinflussung durch die Figurenrede wiederum (ähnlich wie bei erlebter Rede) (vgl. FLEISCHERMICHEL 1977: 225) vom Erzähler unterschiedlich dosiert werden kann. Von der erlebten Rede und der erlebten Reflexion unterscheidet sich somit die figurenbeeinflußte Erzählerrede eben in dem Grad der Beeinflussung durch die 
Figur: während bei erlebter Reflexion und noch mehr bei erlebter Rede die Figurenund Erzählerperspektive fast völlig übereinstimmen (erlebte Rede kann bisweilen mit direkter bzw. indirekter Rede verglichen werden, gibt es bei der figurenbeeinflußten Erzählerrede - sprachlich gesehen - meistens lediglich einzelne Spuren der Figurenbeeinflussung, wobei auch die Perspektive und die damit einhergehenden syntaktischen Parameter (u. a. die Personen- und Tempuswahl) ausschließlich von dem Erzähler her bestimmt werden.

Tabelle I: Abgrenzung der Rededarstellungsformen

\begin{tabular}{|c|c|c|c|c|c|c|c|c|}
\hline & $\begin{array}{l}\mathrm{E} \\
\mathrm{ER}\end{array}$ & (IM) & AR & FBER erRf & IR & erRe & IM & $\begin{array}{l}\mathrm{F} \\
\mathrm{DR}\end{array}$ \\
\hline Modifikation der FR & - & - & + & + & $(+)$ & $(-)$ & - & - \\
\hline Komprimierung der FR & - & - & + & $(+) \quad(+)$ & $(+)$ & - & - & - \\
\hline Redekennzeichnung & - & + & - & $(-)$ & + & $(-)$ & + & + \\
\hline $\begin{array}{l}\text { Beeinflussung der ER } \\
\text { durch die FR }\end{array}$ & - & - & $(-)$ & $(+)(+)$ & + & + & & \\
\hline Vermittleradressat & - & + & - & $(+)$ & - & - & + & $(+$ \\
\hline Adressat & $\mathrm{L}$ & L & $\mathrm{L}$ & L & L & $\mathbf{L}$ & $\mathbf{L}$ & $\mathrm{L}$ \\
\hline Diktion der F & - & - & $(-)$ & $(-)(+)$ & $(+)$ & $(+)$ & + & + \\
\hline Gedanken der F & - & - & $(-)$ & $(+)$ & + & + & + & + \\
\hline Diktion des $\mathrm{E}$ & + & + & + & + & $(+)$ & $(+)$ & - & - \\
\hline Gedanken des E & + & + & + & + & - & - & - & - \\
\hline
\end{tabular}

\section{Legende:}

$\begin{array}{lll}\text { E - } & \text { Erzähler } & \text { erRf - erlebte Reflexion } \\ \text { F - } & \text { Figur } & \text { IR - indirekde Rede } \\ \text { FR - } & \text { Figurenrede } & \text { erRe - erlebte Rede } \\ \text { L - } & \text { Leser } & \text { IM - innerer Monolog } \\ \text { ER - } & \text { Erzählerrede } & \text { (IM) - innerer Monolog auf der } \\ \text { AR - } & \text { abstrahierte Rede } & \text { Erzählerebene } \\ \text { FBER } & \text { figurenbeeinflußte } & \text { DR - direkte Rede } \\ & \text { Erzählerrede } & \end{array}$

Tabellarisch ließen sich die Unterschiede zwischen den einzelnen Redeformen mit Hilfe des Vergleichs einiger relevanter Merkmale der Rededarstellungstypen skizzieren, wie aus der Tabelle I hervorgeht. In der Tabelle sind für einzelne Redeformen die folgenden Rubriken vorgesehen: Gedanken des Erzählers, Diktion des Erzählers, Gedanken der Figur, Diktion der Figur, Adressat, Vermittleradressat, Beeinflussung der Erzählerrede durch die Figurenrede, typische sprachliche Veränderungen, und zwar Redekennzeichnung sowie (quantitative) Komprimierung und (qualitative) Modifikation der ursprünglichen Figurenrede:

Der tatsächliche Adressat ist immer der Leser des Textes, ein Vermittleradressat tritt auf, wenn die ursprüngliche Mitteilung (scheinbar) nicht unmittelbar dem Leser gewidmet ist (in direkter Rede und in beiden Varianten des inneren 
Monologs). Beeinflussungen der Erzählerrede durch die Figurenrede erfolgen, wo sich die Perspektiven der Figur und des Erzählers überlappen. Die einzelnen Rededarstellungstypen sind in der Tabelle so angeordnet, daß von links nach rechts die Einwirkungen der Figurenrede zunehmen, während die des Erzählers abnehmen. Der innere Monolog ist zweimal vertreten, je nachdem, ob es sich um den inneren Monolog der Figur handelt (kein Beleg in unserem Textkorpus), oder aber es denkt der Erzähler als eine der Figuren des primären Kommunikationsereignisses in erster Person bei sich selbst nach (z. B. Satz 58). Je mehr wir uns in Richtung von E (Erzähler) auf F (Figur) hin bewegen, um so bedeutender werden Gedanken und Diktion der Figur, während der Einfluß des Erzählers nachläßt. In Übereinstimmung damit lassen auch die Komprimierung und andere durch den Erzähler durchgeführte Modifikationen in Richtung auf die Figur hin nach. Diese Verhältnisse sehen konkret folgendermaßen aus: Für die Erzählerrede und den vom Erzähler geführten inneren Monolog ist typisch die Diktion des Erzählers ohne jeglichen Einfluß der Figur. Die abstrahierte Rede ist eine fast völlige (quantitative und qualitative) sprachliche Modifikation der Figurenrede durch den Erzähler. In der figurenbeeinflußten Erzählerrede gibt es bereits einzelne Spuren der Einwirkungen der Figurenrede (die Komprimierung und Modifikation seitens des Erzählers sind nicht mehr so intensiv). In der erlebten Reflexion findet man bereits Nachahmungen der Figurenrede vor, für die indirekte Rede sind jedoch in erster Linie die vom Erzähler vorgenommenen syntaktischen Veränderungen der Figurenrede typisch, während die erlebte Rede fast eine wörtliche Übertragung der Figurenrede ist (daher auch als eine Art (in)direkte Rede auffaßbar). Innerer Monolog (auf der Figurenebene) und direkte Rede sind die authentischsten Dokumentationen der Figurenrede. Umgekehrt proportional ist also das Verhältnis, in dem Komprimierung und qualitative Modifikationen der Figurenrede einerseits und die linguistisch faßbaren Merkmale der Redekennzeichnung andererseits stehen, die in der Regel um so ausgeprägter sind, je stärker der (sprachliche) Einfluß der Figur wird, weil nur so eine (rezeptive) Abgrenzung der Komponenten der Figurenrede von denjenigen der Erzählerrede gewährleistet ist (siehe Tabelle II). Einzelne Rededarstellungstypen bilden sich dort heraus, wo schwerpunktmäßig distinktive Kombinationen gewisser Merkmale entstehen.

Eine genaue Auseinanderhaltung einzelner Redeformen - obwohl manchmal schwer durchführbar - ist auch von Nutzen bei der empfängerorientierten komplexen Textanalysen, wo klar faßbare Abgrenzungskriterien (u. a. metakommunikative redekennzeichnende Hypersätze als Gliederungsmerkmale von Kommunikationsebenen) zur Identifizierung von Textsegmenten und ihrer Teilfunktionen im Text beitragen. Allerdings ist auch auf der untersten Ebene, bezüglich einzelner Ausdrucksmittel, eine genaue Festlegung der Rededarstellungsmöglichkeiten bzw. eine exakte Definition einzelner Rededarstellungsformen in Abhängigkeit von der Textstruktur von Bedeutung, und zwar bei der Bestimmung der kommunikativen Funktionen von Ausdrucksmitteln. Es ist nämlich nicht irrelevant, von wem einzelne sprachliche Elemente ausgehen. Stößt man z. B. auf umgangssprachliche Ausdrucksmittel in der Erzählerrede, so können diese umgangssprachlichen Ausdrucksmittel andere kommunikative Funktionen erfüllen, als wenn sie der Figur - einem anderen Teilnehmer des primären Kommunikationsereignisses (etwa im Fall der 
Tabelle II: Erzählerperspektive versus Figurenperspektive

EINFLUßBEREICH DER

FIGUR

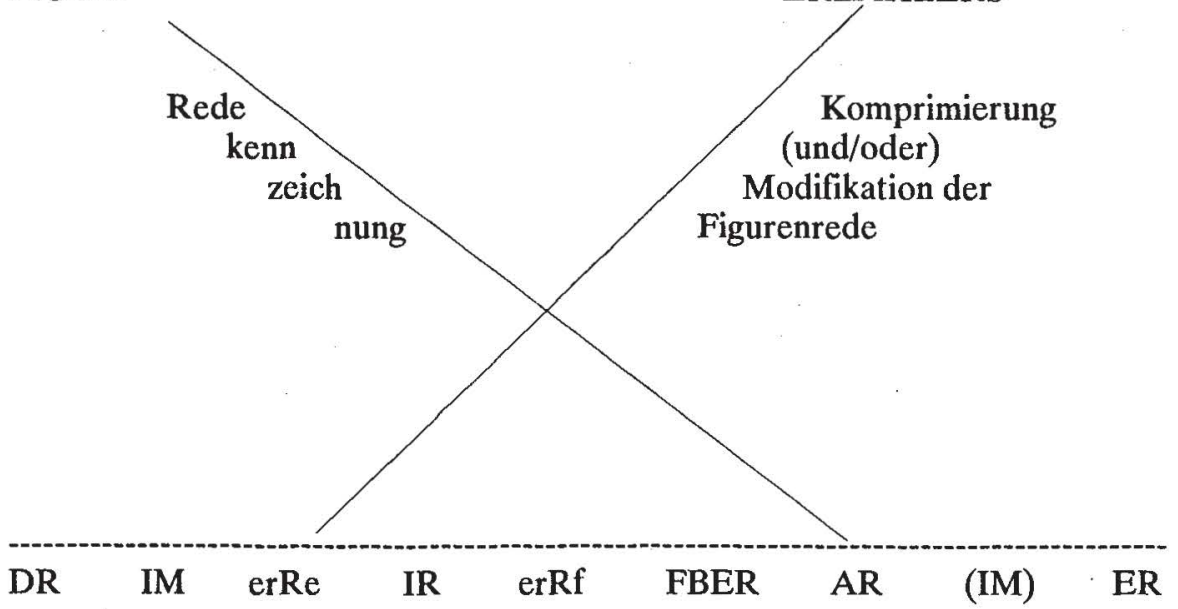

figurenbeeinflußten Erzählerrede oder der erlebten Rede) zuzuschreiben sind. Im ersten Fall hätten wir es vermutlich mit einer Art Identifizierung; Bagatellisierung der Probleme oder auch Distanzierung davon seitens des Erzählenden zu tun, im zweiten Fall könnten dieselben umgangssprachlichen Ausdrucksmittel vielmehr eine Art Figurencharakterisierung (im Sinne von Sprachporträt) zum Ausdruck bringen. $<26>$

Die Unterscheidung von Handlungs- und Situationsebene in der (Reise) erzählung bringt neue Dynamik in die Analyse dieser Textsorte mit sich, weil sich durch diese Unterscheidung die Ereignisse, auf denen formal das in der Erzählung beschriebene Geschehen aufgebaut ist (Handlungsebene der Erzählung), von jenen Ereignissen auseinanderhalten lassen, die auf den ersten Blick nur als Kulisse für das grundlegende Geschehen dienen (Situationsebene der Erzählung), obwohl über diese Kulisse das Geschehen manchmal schneller voranschreitet als auf der Handlungsebene selbst. (Vgl. SCHMIDT et al. 1981: 113) In der Situationsphase werden meistens Bedingungen für eine Umschaltung auf die Handlungsebene vermittelt, und umgekehrt, die Handlungsebene baut auf Gegebenheiten der Situationsebene auf. Besondere Bedeutung kommt Zeit- und Ortsangaben zu (vgl. GÜLICH-HEGER-RAIBLE 1979: 85, 91). Die Situationsebene ist um so häufiger, je stärker über das grundlegende Geschehen hinaus das sekundäre Geschehen differenziert ist, das oft eine Widerspiegelung subjektiver Reflexionen des Erzählers ist.

Quantitativ gesehen überwiegen in den von mir analysierten 67 Sätzen mit umgangssprachlichen Elementen die Beispiele der Situationsebene signifikant gegenüber der Handlungsebene im Verhältnis von $4: 1$ (54 Situationsebenen gegenüber 14 Handlungsebenen). Angenommen, daß die Existenz einer Handlungsebene für das Erzählen verfahrensspezifisch und daß das Geschehen als 
Gegenstand des konkreten Erzählens durch Tätigkeiten gekennzeichnet sei (vgl. SCHMIDT et al. 1981: 113), kann auch aufgrund der obigen einfachen statistischen Ausrechnung bestätigt werden, daß wir es mit einer (Erlebnis)Erzählung zu tun haben, in der die äußeren Prozesse und Handlungsphasen sehr stark durch die subjektive Stellungnahme der Erzählerin durchfiltert werden. Vor diesem Hintergrund wird aber die Präferenz für den Gebrauch der Umgangssprache einleuchtend.

Bei der Bestimmung der kommunikativen Funktion des Mustertextes knüpfe ich an das an, was zur kommunikativen Funktion im allgemeinen unter 2. ausgeführt wurde.

Der Text hat eine direkte kommunikative Funktion, seine kommunikative Funktion kann aber auch indirekt sein.(S. Tabelle III.)

Tabelle III: Kommunikative Textfunktionen

direkt

(stabil, objektiv)

allgemein

(absolut)

erlebnisbetont

informieren indirekt

(variabel, subjektiv)

allgemein

(absolut)

speziell

(thematischgegenständlich)

aktivieren

Verteidigen des

Trampens, der Moral der Tramper, auch der betagten

Die direkte kommunikative Funktion könnte unterteilt werden in allgemeine und spezielle kommunikative Funktion des Textes, und sie stimmt prinzipiell mit der kommunikativen Absicht, mit dem dominanten Kommunikationsplan eines Textes überein (vgl. SCHMIDT et al. 1981: 43 und SCHMIDT et al. 1977: 148). Die direkte allgemeine kommunikative Funktion unseres Mustertextes wäre'somit eine erlebnisbetont informierende (vgl. zur Bestimmung der Textfunktion in HEUSINGER 1981a: 555). An dieser Stelle sei hervorgehoben, daß die Gesamttextfunktion dem kommunikativen Gesamtplan eines Textes entspricht und als eine Art Resultante der kommunikativen Funktionen (und somit Teilpläne) einzelner Textsegmente (Absätze usw.) zusammengesetzt ist. ${ }^{<7>}$ Die direkte spezielle Textfunktion ist mehr thematisch-gegenständlich bedingt und daher mehr einzeltextspezifisch. In unserem Fall geht es darum, daß der Text unterhalten, bilden, belehren soll.

Die indirekte Textfunktion ist etwas komplizierter darstellbar. Indirekt heißt sie deshalb (vgl. auch 2.b), weil sie nicht unmittelbar erkennbar ist, weil sie indirekt signalisiert wird (vgl. BRINKER 1983: 142), weil sie (manchmal) durch geheime Intentionen (vgl. a.a.O.: 132), nicht durch manifeste, sondern durch verdeckte Kommunikationsabsichten (vgl. SCHMIDT et al. 1977: 148) gekennzeichnet ist. ${ }^{<28>}$ 
Bei der Erschließung der indirekt ausgeprägten Textfunktion hilft man sich mit der propositionalen Analyse (vgl. HEUSINGER 1981a: 552 f.), mit verschiedenen "Indizien" (vgl. BRINKER 1983: 132), "Signalen" (vgl. BIEBERLE 1987: 200) und "Indikatoren" (vgl. HEUSINGER 1987a: 196). Die allgemeine indirekte Textfunktion wäre in unserem Mustertext eine aktivierende (vgl. auch SCHMIDT et al. 1981: 109). Über die Grundabsicht des Autors hinaus, seine Gefühle, seine Erinnerungen an verschiedene (ausgewählte) Erlebnisse durch diesen Text erlebnisbetont informativ und konkret $\mathrm{zu}$ gestalten, ist allerdings potentiell auch möglich, daß der Autor - vielleicht mehr unbewußt - z. T. auch das Ziel verfolgt haben kann, mit einem Text in der Zeitungssparte "Reise" verschiedentlich, (womöglich) auch für die Zeitschrift, Werbung zu machen. ${ }^{<9>}$ Die spezielle indirekte kommunikative Textfunktion, diejenige also, die - analog zur speziellen direkten Textfunktion - thematisch-gegenständlich geprägt ist, sehe ich u. a. in einem Befürworten des beschriebenen Unternehmens, darin, daß die Autorin (vermutlich) ihre moralischen Prinzipien verteidigen, ihre Sympathie für die Tramps und für das Trampen im allgemeinen, ja, auch für die ältere Generation zum Ausdruck bringen möchte.

Diese indirekte Ausprägung der Textfunktion ist ein schillernder Begriff, er ist nämlich nicht problemlos objektiv bestimmbar, sondern vielmehr auch von dem jeweiligen Textrezipienten abhängig (vgl. SANDIG 1986: 96)(vgl. auch 2.c). Das hat mit dem Weltwissen des Rezipienten ${ }^{<0>}$ zu tun, mit seinen Anschauungen, Interessen, Absichten, mit seinen übergeordneten Kommunikations- und Tätigkeitszielen u.d.m. Ein junger Leser sieht beispielsweise in unserem Text womöglich eine Art Anregung zur Tat, Verteidigung des Geistes der "Reiserei" per Anhalter, eine ältere Dame wird sich kaum zur Nachahmung angeregt fühlen, vielmehr wird sie im Text eine Art Unterhaltung, aber auch Warnung u. ä. rezeptiv realisieren. $<31>$

Somit ließe sich die indirekte Textfunktion als variabler Teil (variable Komponente) der Textfunktion auffassen, auch für den Fall, daß der Textproduzent absichtlich versteckte Absichten in dem Text enkodiert hat, die indirekte Wirkungen erzielen sollten (vgl. 2.). ${ }^{<32>}$

Mit der Bestimmung der kommunikativen Funktion des Textes wäre nun die notwendige Grundlage geschaffen, auf der ich Genaueres zur kommunikativen Funktion der umgangssprachlichen Ausdrucksmittel aufbauen kann.

Bevor zur konkreten Sprachanalyse des Mustertextes übergegangen wird, sei einiges zu dessen Textsorte erörtert. Textsorten, als jene Abstraktionsstufen einer (je unbegrenzten) Reihe von ähnlichen Texten aufgefaßt, die, eine Menge spezifischer distinktiver Merkmale - "typische Kombinationen kommunikativer Regeln" (HENNIG-HUTH 1975: 140) - aufweisend, ein identifizierbares Gepräge erhalten ${ }^{<33>}$, sind komplexe Objektivierungen konkreter Kommunikationspläne. Als solche eignen sich die Textsorten als Konstante bei Untersuchungen verschiedener Sprachphänomene. (Vgl. BRINKER 1983: 147 sowie SCHMIDT et al. 1981: 158).

Ich gehe in meiner Textklassifikation von dem SCHMIDTschen Ansatz aus, daß "mit der Entsprechung von Kommunikationsabsicht und Textfunktion das Prinzip für 
die Einteilung von Texten gegeben /ist/" (SCHMIDT et al. 1981: 43). (Vgl. BEAUGRANDE-DRESSLER 1981: 189, 191).

In unserem Fall handelt es sich um einen informierenden (Textklasse), und zwar erlebnisbetont informierenden Text (Texttyp). Da das dominante KV Erzählen ist, können wir nebst Textklasse und -typ auch die Textart bestimmen, und diese ist die Erzählung. Es wird davon erzählt, was die Autorin (Erzählerin) auf einer Reise erlebt hat (Zeitungssparte "Reise"), folglich ist die Textsorte eine Reiseerzählung. Es geht hier aber um eine Pressereiseerzählung (eine Art Alltagserzählung ${ }^{<3>}$ ), und nicht um eine literarische Reiseerzählung (etwa im Sinne HEINEs "Die Harzreise"), womit auch der Tätigkeitsbereich (Journalistik, Kunst) ein textsortendifferenzierendes Kriterium darstellt. Trotz gewissen hypostasierten touristisch-werbenden Elementen in einem Zeitungstext könnte man jedoch den Pressereiseerzählungen schwerlich in. erster Linie den Charakter von Gebrauchstexten zuschreiben; auch ihnen haften nämlich weitgehend literarisch-belletristische Elemente an.

Neben diesen textlinguistischen Kriterien lassen sich bei der Textklassifizierung noch andere, mehr inhaltlich-thematische Aspekte herausarbeiten.

Verbreitet ist in terminologischer Hinsicht die allgemeine Bezeichnung "Reisebericht", die jedoch infolge theoretisch-linguistischer Erkenntnisse einer Präzisierung bzw. Korrektur bedarf. Wenn wir nämlich mit STARKE (in SCHMIDT et al. 1981: 92) und mit BIEBERLE-GRAEBER (ibid: 109) beachten, daß Gegenstände (also Statisches) (sachbetont) beschrieben oder (erlebnisbetont und subjektbezogen) geschildert werden, Prozesse (Handlungen, also Dynamisches) dagegen (sachbetont) berichtet (bei singulären Ereignissen), (erlebnisbetont) erzählt (Geschehnisse, komplexe Sachverhalte), bei wiederholtem oder wiederholbarem Geschehen jedoch (mehr oder weniger sachbetont) auch beschrieben werden, dann kann bei erlebnisbetonten informativen Texten insgesamt nur von einer (Reise)erzählung die Rede sein (vgl. SCHMIDT et al. 1981: 93, 109), wenn auch dem Umstand Rechnung zu tragen ist, daß gemäß dem bereits erwähnten hierarchischen Dominanzprinzip das Erzählen als dominantes KV bzw. als Gesamtverfahren auf niedrigeren (elementareren) Textsegmentebenen auch andere konstitutive $\mathrm{KV}$, wie $\mathbf{z}$. B. Berichten, Beschreiben, Schildern voraussetzt und somit einzelne Teiltexte u.U. für sich allein auch als Berichte, Beschreibungen, Schilderungen fungieren könnten. $<36>$

Abschließend seien hier einige Charakteristiken der Textart Erzählung angeführt, die weitestgehend auch für die Textsorte Reiseerzählung Geltung haben. Dieser Textart liegt das KV Erzählen zugrunde, dessen grundlegende FKM 'deskriptiv', 'subjektiv', 'erlebnishaft', 'konkret', 'emotional einwirkend' (vgl. HEUSINGER 1984: 105) zugleich die Koordinaten von Erzählungen im wesentlichen mitbestimmen. Gegenstand der Erzählungen sind komplexe, abgeschlossene Sachverhalte, die aus einer beliebig dosierten Distanzhaltung des Erzählers heraus präsentiert werden (vgl. SCHMIDT et al. 1981: 110 f.). Für Erzählungen ist kein gefestigtes, gängiges, typisches, strenges Kompositionsmuster (wie bei einigen anderen Gebrauchstextsorten der Sachprosa, wie etwa Argumentationstexten; vgl. 
SCHMIDT et al. 1981: 40 f.) verbindlich, dennoch kann man auch bei ihnen eine häufig vorkommende Anordnung der Kompositionselemente in einem Spannungsbogen (oder mehreren Spannungsbögen) mit einem oder mehreren Kulminationspunkten (vgl. zum Kommunikationsplan des Mustertextes in 5.1.) verfolgen. Typisch sind auch Abwechslungen von Handlungs- und Situationsebene (vgl. SCHMIDT et al. 1981: 113). Da es sich um einmalige individuelle Geschehnisse handelt, hängt die thematische Progression unmittelbar mit Veränderungen von Schauplätzen und Zeitphasen des Geschehens zusammen (vgl. SCHMIDT et al. 1981: 110). Auch der Ablauf der Geschehnisse, Zeitraffung und -dehnung, Rückblenden und Vorgriffe tragen zur Spannung in Erzählungen bei. Das alles bedingt auch "eine besondere stilistische Kennzeichnung des Textes, die mit den Stilmerkmalen 'anschaulich', 'emotional', 'egotistisch' näher angegeben werden kann" (HEUSINGER 1984: 105).

Daß man bei einer solchen Textart den Einsatz von "sehr differenzierte/m/ Sprachmaterial" (SCHMIDT et al. 1981: 112) voraussetzen kann, steht außer Zweifel. Besonders ist noch $\mathrm{zu}$ erwarten, daß umgangssprachliche Ausdrucksmittel bedeutende kommunikative Funktionen zu erfüllen haben werden. Das ist nun auch Gegenstand der folgenden Sprachanalyse.

\subsection{Die Sprachanalyse des Mustertextes (auszugsweise)}

\section{1. "Na, willste mit?"}

Kommunikationsebene: III. Grades, Rededarstellungsform: direkte Rede, Erzählebene: Situationsebene

KV: Fragen; Anregen ${ }^{<37>}$, FKM ${ }^{<38>}$ : 'inzitativ' + 'Aktion futur. sprachl.'

Lexik: na: umgangssprachliche Kontaktpartikel, umgangssprachliches Eröffnungssignal (vgl. KEMPCKE et al. 1984;

mitwollen $^{<39>}$ : umgangssprachlich für "mitkommen wollen, mitfahren wollen" (KEMPCKE et al. 1984)

Morphologie: willste: umgangssprachliche Zusammenziehung von willst $\mathrm{du}^{<40>}$

Sytax und Stileme: Einfachsatz (3 Wörter)

Kommunikative Funktionen der umgangssprachlichen Ausdrucksmittel:

dominante: Inoffizialität, Spontaneität der Stimmung - Kontaktherstellung

begleitende: Bildhaftigkeit - Unmittelbarkeit des Erlebnisses, Eröffnung des Textrahmens, Sprachporträt - idiolektale Inertion.

Die kommunikative Funktion des 1. Absatzes als Teiltextes ist anders als die kommunikative Funktion des Gesamttextes. Es wurde schon oben festgestellt, daß es sich in diesem Fall um einen aktivierenden (Teil)plan handelt, und zwar um die Unterart Interessieren. Damit stimmt auch die Teiltextfunktion überein und daraus leiten sich die kommunikativen Funktionen der umgangssprachlichen Ausdrucksmit- 
tel ab, gleich am Textbeginn einen echten, unmittelbaren Kontakt mit dem Leser anzuknüpfen, der den Leser interessieren und dafür gewinnen soll, mit der Lektüre fortzusetzen. Das deckt sich auch mit dem Charakter des KV Fragen, das hier nicht als inventives, sondern als inzitatives, kontaktives KV fungiert: der Kraftfahrer lädt mit seiner Frage die trampende Dame ein, mit ihm zu fahren, denn aus der Situation (die Dame mit hochgerecktem Daumen am Straßenrand) geht deutlich hervor, daß die Dame trampen möchte. So kommt es zu einer interessanten Überlagerung der Kommunikationsebenen im Text: während der Kraftfahrer auf der III. Kommunikationsebene mit seiner Frage die Tramperin (ältere Dame) zum Mitfahren anregen will (gleich zu Beginn des Textes Umgangssprache und Duzen als ein Signal des vergleichbaren Sozialstatus), lädt der Autor (die Autorin) des Textes, indem er diesen Dialog in direkter Rede am Textbeginn anführt, den Leser indirekt zur Fortsetzung der Lektüre ein (II. Kommunikátionsebene). Eine bedeutende Rolle spielt also pragmatisch eben auch die Einstiegsphase des Textes. "Das berühmte Spiegelstatut von 1949 gibt nicht mehr als ein paar allgemeine Starthilfen für neue Arbeiten: ... den Hinweis darauf, daß es nützlich sei, den Leser mit dem ersten Satz wie mit einer Fangschnur festzuhalten; ..." (NELLEN 1986: 119).

127. Der Junge bleibt friedlich, sagt dann, er dürfe sowieso niemanden mitnehmen, tanken muß er auch, da kann ich raus.

Kommunikationsebene: II. Grades, Rededarstellungsform:

Erzählerrede + indirekte Rede, Erzählebene: Situationsebene

KV: Mitteilen ${ }^{<1>}$, FKM: 'deskriptiv' + 'erlebnishaft'

Lexik: sowieso: umgangssprachlich für "ohnehin" (KEMPCKE et al. 1984)

da: vgl. Satz $22<42>$

rauskönnen: umgangssprachlich für "hinausgehen können" (WAHRIG 1986/87)

Morphologie: raus: umgangssprachliche Variante von "hinaus, heraus" (vgl. DUDEN 1973 sowie Sätze 48 und 159)

Sytax und Stileme: zusammengesetzter Satz, Hypotaxe (19 Wörter); Asyndeton, Auslassung des Personalpronomens, Klimax

Kommunikative Funktionen der umgangssprachlichen Ausdrucksmittel:

sowieso:

dominante: Inoffizialität der Stimmung

begleitende: Sprachporträt - Charakterisierung der Figur + idiolektale Inertion da, rauskönnen:

dominante: subjektive emotionelle Einstellung - Ungeduld,

Unzufriedenheit, Aufregung

begleitende: Sprachporträt - Charakterisierung der Figur + 
Die kommunikativen Funktionen der umgangssprachlichen Elemente lassen sich in Satz 127 am besten bestimmen, wenn wir die Äußerung als Ganzes und zugleich als Bestandteil des Textes betrachten. Es geht hier um einen zusammengesetzten Satz, in dem allein das Asyndeton konzis, komprimiert und spannend wirkt (vgl. FLEISCHER-MICHEL 1977: 126). Auch die Verflechtung (Kombination) von Erzählerrede und indirekter Rede trägt das Seine zur Bidlhaftigkeit des Darstellens (Erzählens) bei. Besonders interessant ist die in den drei uneingeleiteten Nebensätzen auftauchende indirekte Rede. Im 1. Nebensatz befindet sich in indirekter Rede der Konjunktiv I (kombiniert mit dem umgangssprachlichen Lexem "sowieso"), im 2. Nebensatz der Indikativ, im 3. Nebensatz dagegen der Indikativ zusammen mit der umgangssprachlichen lexikalischen Variante "rauskönnen". In diesem Fall handelt es sich um eine Art Klimax, wodurch zum Ausdruck gebracht wird, wie die Ungeduld des Fahrers, seine Unzufriedenheit zunehmen, nachdem er in seiner Absicht von der Tramperin zurückgewiesen worden ist. In der 1. Phase der indirekten Rede begegnet der Konjunktiv I, der für die deutsche Sprache (Schriftsprache!) der neutrale, nichtexpressive Modus der indirekten Rede ist (vgl. FLEISCHER-MICHEL 1977: 222) und der in Satz 127 womöglich die offizielle Vorschrift äußert, daß LKW-Fahrer in der Tat keine Tramper mitnehmen dürften. Umgangssprachliches Lexem "sowieso" ist dabei bereits eine persönlich gefärbte Bekräftigung dieser Tatsache. In der 2. Phase ("tanken imuß er auch") steht schon der Indikativ Präs., der m. E. jedoch nicht die für den Indikativ in der indirekten Rede typische "positive Einstellung zur Äußerung" (ibid.) ausdrückt, sondern eher eine stärkere Distanzierung von dem offiziellen Charakter der Äußerung und den Übergang in die Sphäre des Privaten, wo auch die Emotionen zum Ausdruck kommen (können), z. B. das Beleidigtsein, Ärger, was am intensivsten in der 3. Phase der indirekten Rede ("da kann ich raus") formal und inhaltlich geäußert wird, in der die Wirkung des Indikativs durch die umgangssprachliche Variante "rauskönnen" hervorgehoben wird. Die Erzählerperspektive überlagert in der indirekten Rede die Figurenperspektive (des Fahrers), und das findet seinen Niederschlag in der Sprache. Aufgrund der sprachlichen Gegebenheiten ließe sich also schwer die Entscheidung treffen, ob es sich in Satz 127 vorwiegend um eine Versprachlichung des Unwillens der Figur (des Fahrers) handle oder vorwiegend um die Darstellung der Betroffenheit der Erzählerin bzw. wie das Verhältnis zwischen den beiden Perspektiven ist. Außer Zweifel steht jedoch, daß auch umgangssprachliche Elemente - in Verbindung mit den anderen oben beschriebenen - zur Versprachlichung der unangenehmen und gespannten Stimmung beitragen, die vor der Trennung beider Kommunikationspartner gesteigert wird. Das alles stimmt auch völlig mit einigen grundlegenden FKM des Erzählens überein (wie z. B. 'modifikativ', 'erlebnishaft', 'emotional einwirkend') wie auch mit der KF des gesamten Textes (erlebnisbetontes Informieren).

200. Ich darf die Anhalterei nicht hochjubeln.

Kommunikationsebene: II. Grades, Rededarstellungsform: 
Erzählerrede, Erzählebene: Situationsebene

KV: (zusammenfassendes) Feststellen, FKM: 'deskriptiv' + 'modifikativ'

Lexik: Anhalterei: umgangssprachlich für "das Trampen, das

Reisen per Anhalter"; abschätzige Individualvariante,

wahrscheinlich durch Analogie zu "Reiserei" (vgl. Satz 202) <43>

hochjubeln: umgangssprachlich für "jemanden/etwas

übertrieben und ungerechtfertigt loben"(BROCKHAUS WAHRIG 1980-1984)

Sytax und Stileme: Einfachsatz (6 Wörter)

Kommunikative Funktionen der umgangssprachlichen Ausdrucksmittel:

dominante: subjektive emotionelle Einstellung - Beunruhigung + Distanzierung begleitende: Anschaulichkeit, Sprachporträt - idiolektale Inertion, Isotopiekette.

Mit diesem Satz eröffnet die Erzählerin den letzten Teilplan (D) im Text: das ist eine zusammenfassende, beurteilende Bilanz der Erfahrungen mit dem Trampen, auf denen auch die bewußte, im allgemeinen eher negative Einstellung der Erzählerin zum Trampen als Erscheinung beruht. Beide umgangssprachliche Lexeme (Anhalterei, hochjubeln) weisen in diesem Kontext auch negative konnotative Assoziationen auf, was eindeutig eine grundsätzlich ablehnende emotionelle Einstellung der Trampenden zum Trampen als solchem, eine Distanzierung davon verbalisiert. In der Isotopiekette im Text, die sich auf verschiedene Bezeichnungen des Reisens per Anhalter bezieht (Trampen, Autostopp usw.), ist der mit negativer Konnotation versehene Begriff "Anhalterei" gerade in dieser Schlußphase zum ersten Mal verwendet. Das bedeutet eine Abrechnung mit der Romantik, mit der die Autorin im Text die ganze Zeit (latent) liebäugelt. Zutage kommt eine neue Erkenntnis und eine aufrichtige Einschätzung alles Erlebten. Auch im Zeichen dieser Ernüchterung bewähren sich umgangssprachliche Ausdrucksmittel als ein sehr geeignetes Instrument zur Versprachlichung verschiedentlich gefärbter Emotionen. Auch syntaktische Ausdrucksmittel (hier z. B. prägnanter Einfachsatz aus nur 6 Wörtern) stehen im Dienste einer solchen Ausdrucksweise.

\subsection{Umgangssprachliche Ausdrucksmittel}

Die Umgangssprachlichkeit der deutschen Lexik ist nicht immer genau bestimmbar. Die Ungewißheit widerspiegelt sich in Wörterbüchern, sie wird aber auch durch die sprachliche Kompetenz der deutschen Muttersprachler bestätigt. Die Bestimmung der Umgangssprachlichkeit eines Lexems ist bisweilen von dem Kontext abhängig, bisweilen ist die Umgangssprachlichkeit des Lexems auch in demselben Kontext unstabil. Das hat wenig mit national bedingten sprachlichen Besonderheiten der deutschen Sprache zu tun. Bei der umgangssprachlichen Lexik sind noch die fol- 
genden Aspekte interessant: Besonderheiten der Wortbildung, Umgangssprachlichkeit der Lexik und die Sprachökonomie, idiolektale Besonderheiten, zeitliche Prägung, Allerweltswörter, onomatopoetische Besonderheiten, Idiomatizität.

Morphologische ugs. Ausdrucksmittel sind selten, ihre Umgangssprachlichkeit ist jedoch von dem Kontext meist unabhängig.

Von der umgangssprachlichen Syntax kann nur unter gewissen Bedingungen gesprochen werden, weil einzelne syntaktische Besonderheiten, Stileme und Abweichungen vom normativen Sprachgebrauch (z. B. kurzer Einfachsatz, Parataxe, Ellipse, Prolepse, Anapher, Parenthese, Ausrahmung, Nachtrag, Anrede, Gliederungssignale, eingeschobene Interjektionen, syntaktischer Parallelismus, markierte Satzgliedfolge, Aposiopese, Anakoluth, Asyndeton, Polysyndeton, Wiederholung, Appositionen u.a.m.), nicht an sich selbst - im Sprachsystem - umgangssprachlich sind, sondern erst, wenn einige andere Kommunikationsbedingungen erfüllt sind (Textsorte, Funktionalstil, Thematik u.a.m.)(vgl. Anm. ${ }^{<49>}$ ). Die umgangssprachliche Syntax in der Schriftsprache kommt der Syntax der gesprochenen Sprache nahe ${ }^{<45}$, wobei sie in der Schriftsprache, wie dies für alle anderen umgangssprachlichen Ausdrucksmittel gilt, mehr oder weniger stilistisch markiert ist.

Aus der phänomenologischen Auslegung der Umgangssprache (vgl. 3.) geht hervor, daß umgangssprachliche Ausdrucksmittel mit normalsprachlichen Ausdrucksmitteln, aber auch umgangssprachliche Ausdrucksmittel aus verschiedenen Ebenen des Sprachsystems miteinander kombiniert werden. Dabei können sich pragmatische Einwirkungen summieren (steigern) oder auch (scheinbar) abschwächen. Es kann z. B. registriert werden, daß umgangssprachliche lexische und umgangssprachliche syntaktische Ausdruckselemente einander entgegenwirken (vgl. Sätze 118 und 166). Während die Lexik darin mehr dazu neigt, das Seriöse oder/und Gefährliche einer Situation abzuschärfen, hat die knappe (auch elliptische) Syntax eher eine spannende und dramatisierende Wirkung. Das bedeutet keinesfalls eine Disharmonie im Gebrauch des verfügbaren Ausdrucksmittelinventars. Im Gegenteil, solche unerwarteten Kombinationen wirken frisch und verwirklichen an den gängigen stereotypen Ausdrucksmöglichkeiten vorbei neue konnotative Nuancen im Ausdruck. So spricht SCHMIDT (1982: 17) mit Recht von dem sog. "anteiligen Zusammenwirken" sprachlicher Mittel bei der Erreichung eines Kommunikationsziels.

\subsection{Die Distribution der umgangssprachlichen Ausdrucksmittel im Mustertext}

In meiner Sprachanalyse kommt es nicht in erster Linie auf quantitative Auswertungen im absoluten Sinne an. Quantitative Aspekte werden im begrenzten Umfang nur im relativen Sinn beachtet, $d$. h. hinsichtlich der Distribution einiger umgangssprachlicher Ausdruckselemente im Text. Dabei verweise ich auf die Auffassung Anne BETTENs: "Gerade die für den Stil eines Werkes ausschlaggebende spezifische Mischung und Verteilung besonderer sprachlicher Phänomene geben bloße Zahlen nicht wieder; das kann nur die Einbeziehung einer gewissen Kontextmenge leisten" (1985: 76 f.). Dennoch will ich zur allgemeinen Orientierung zwei 
Tabelle IV: Distribution der umgangsprachlichen Ausdrucksmittel im Text

KU - Koeffizient der Umgangssprachlichkeit

WA - Wortanzahl

S - Sätze

$\bar{\omega}$

1176
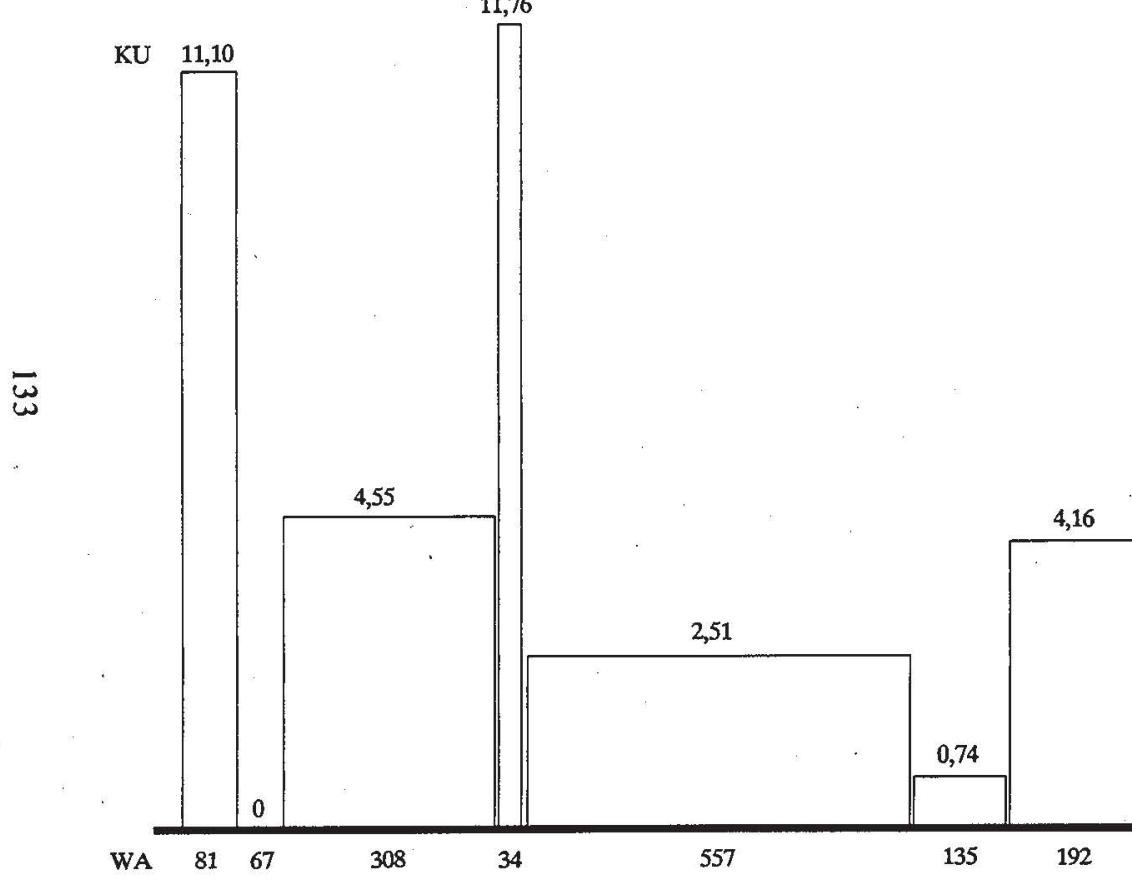

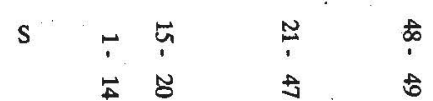

557

135

192

$\begin{array}{lll}8 & 8 \\ \& & \dot{5}\end{array}$

$\stackrel{8}{8}$

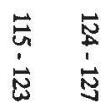

总

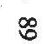

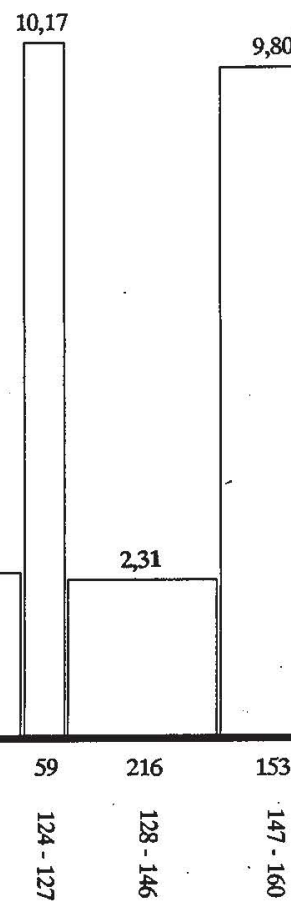

9,80

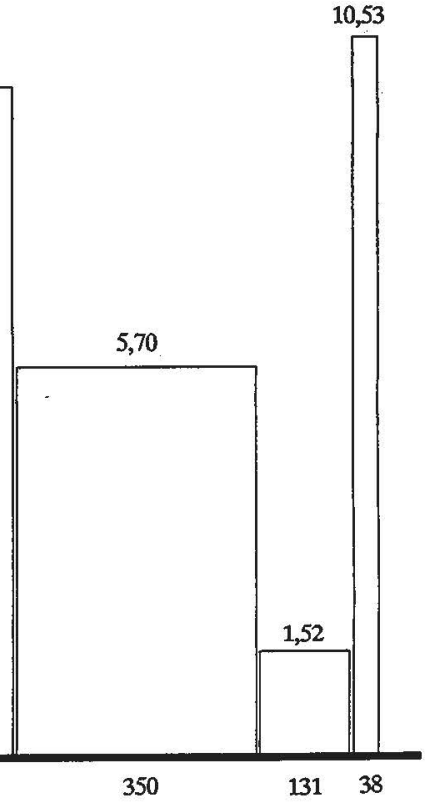

$\dot{\mathrm{s}}$

宙

ष्ष 
statistische Werte bringen: die durchschnittliche (mittlere) Satzlänge (11,9 Wörter) und den Prozentanteil der Einfachsätze aus dem Mustertext $(37,75 \%)$.

Tabelle IV soll als Grundlage für weiterführende Schlußfolgerungen dienen.

Wir sehen, daß im Textsegment vom 1.-14. Satz (aktivierender, interessierender Teilplan; Kontakt mit dem 1. Fahrer), der Koeffizient der Umgangssprachlichkeit (KU) 11,10 \% beträgt. Die durchschnittliche Satzlänge (der Sätze mit umgangssprachlichen Ausdrucksmitteln!) ist 5,6 Wörter. Hier finden wir 4 direkte Reden und 2 Erzählerreden vor. Syntaktische und stilistische Besonderheiten: 5 Einfachsätze, 1 Parataxe, 2 Ausrahmungen, 1 Ellipse, 1 Anapher, ein nachgetragenes unflektiertes adjektivisches Attribut.

Sätze 48-49 (Warnungen vor den Gefahren; Teilplan erlebnisbetontes Informieren) weisen den KU 11,76 aus, die mittlere Satzlänge beträgt 17 Wörter. Neben einer Erzählerrede, einer indirekten Rede und einer figurenbeeinflußten Erzählerrede gibt es hier noch 2 Parataxen, 1 Ersparung des Personalpronomens, interessant ist aber auch der 1. Konditional in Satz 49.

Der knappe Textabschnitt - Sätze 124-127 - (erlebnisbetontes Informieren) weist den KU 10,17 aus, mittlere Satzlänge ist 13,7 Wörter. In ihm sind enthalten: 2 Erzählerreden, 2 indirekte Reden und darüber hinaus folgende syntaktische und stilistische Besonderheiten: 1 Einfachsatz, 2 Hypotaxen, 2 Ellipsen (eine davon als Parenthese), 3 Asyndeta, 1 Ersparung des Personalpronomens, 1 nachgetragenes unflektiertes adjektivisches Attribut, 3 Indikative in indirekter Rede, 1 Klimax.

Der Kontakt mit dem "Mordskerl" ist in Sätzen 147-160 (kommunikativer Teilplan erlebnisbetontes Informieren) geschildert. Für dieses Textsegment sind charakteristisch: KU 9,80, mittlere Satzlänge beträgt 10,8 Wörter. Als Redeformen gibt es: 5 Erzählerreden, 1 erlebte Rede, 1 figurenbeeinflußte Erzählerrede und folgende syntaktische und stilistische Strukturen: 2 Einfachsätze, 3 Parataxen, 1 Hypotaxe, 4 Asyndeta, 2 Ellipsen, 1 Ersparung des Personalpronomens, 1 Anapher, 1 Nachtrag, 1 Anakoluth, 1 Klimax, 1 Alliteration, 1 Konnex (vgl. AGRICOLA 1977: 146).

Im letzten Textsegment (Sätze 200-204), in dem abschließende Bilanz der Erlebnisse gezogen wird (klärender kommunikativer Teilplan; KU 10,53; mittlere Satzlänge 7,7!), finden wir 3 Erzählerreden, 3 Einfachsätze und 1 Klimax vor.

Es geht oben um eine grobe Textsegmentierung, entstanden aufgrund der Verallgemeinerungen, die auf der Verteilung der umgangssprachlichen Elemente im Text beruhen. ${ }^{<7>}$ Diese Gliederung kann daher nur eine beschränkte, auf die hier abgesteckten Untersuchungszwecke zugeschnittene Geltung haben. Dennoch zeichnen sich dabei deutliche Korrelationen ab zwischen den Kommunikationsdeterminanten im Text einerseits und den umgangssprachlichen Realisierungsvarianten andererseits. Die Analyse der Verteilung von lexischen umgangssprachlichen Elementen im Text (mitsamt einigen wenigen morphologischen umgangssprachlichen Ausdruckselementen) gibt nämlich eindeutig Aufschluß darüber, daß diese Verteilung nicht zufällig ist (vgl. SANDIG 1986: 115). Umgangssprachliche Elemente 
treten konzentriert dort auf, wo im Text kommunikativ exponierte Stellen sind: am Textbeginn - bei der Kontaktaufnahme der Erzählerin mit dem 1. Fahrer (und zugleich mit dem Leser!), dort, wo die Trampende vor Gefahren auf einer solchen Reise gewarnt wird (Sätze 48-49), im Kontakt mit dem LKW-Fahrer (Sätze 124-127) und mit dem "Mordskerl" (Sätze 147-160) sowie am Textschluß. Neben diesen 4 Kulminationspunkten (ich ziehe die logisch zusammenfallenden Textsegmente 124-127 und 147-160 zusammen) mit durchschnittlichem KU 10,67 gibt es auch Textabschnitte mit relativ wenig umgangssprachlicher Lexik (und mit wenig morphologischen Ausdrucksmitteln), weiterhin solche mit ganz wenigen umgangssprachlichen Ausdrucksmitteln und einen Abschnitt (Absatz II) mit gar keinem umgangssprachlichen Ausdruckselement. (Vgl. Tabelle IV).

Evident ist in dieser Perspektive z. B. die Opposition zwischen den beiden klärenden Teilkommunikationsplänen (Sätze 15-20 mit KU $=0$ und Sätze 200-204 mit $\mathrm{KU}=10,53 !)$.

Im 2. Spannungsgefüge der Textkomposition (Warnungen : Gefahren erlebt; vgl. in 5.1.) ist der KU ebenfalls (relativ) hoch.

Genauso interessant ist der Einsatz entsprechender Rededarstellungsformen sowie syntaktischer Besonderheiten und der Stileme, wenn diesen Ausdrucksmitteln wie oben angedeutet - auch nicht im voraus der umgangssprachliche Charakter zugeschrieben werden kann.

Auffallend ist, daß in der Kontaktanknüpfung zwischen der Erzählerin und dem 1. Fahrer (Sätze 1-14) die direkte Rede vorherrscht (4 direkte Reden gegenüber 2 Erzählerreden). Hier erfüllt offenbar die mit umgangssprachlichen Elementen durchsetzte direkte Rede eine entsprechende (Kontaktanknüpfungs)funktion. In der textabschließenden Passage (200-204) kommen nur 3 Erzählerreden vor und keine andere Rededarstellungsform! Der pessimistisch-resignierend anmutende Grundton in diesem Teiltext diktierte dem Textproduzenten wohl die Auswahl anderer Ausdrucksvarianten (vgl. auch zur Syntax unten).

Der Gebrauch der indirekten Rede und der figurenbeeinflußten Erzählerrede wäre darauf zurückzuführen, daß die Erzählerin dadurch möglicherweise eine gewisse, bisweilen sogar mokierénde Distanz zu den Prophezeiungen äußern kann (vgl. Satz 49, wo in Kombination der indirekter Rede und der figurenbeeinflußten Erzählerrede das Verb "unken" gebraucht wird, die Distanz aber auch mit dem 1. Konditional hervorgehoben wird). Bemerkenswert ist ein sich leicht abzeichnendes direkt proportionales Abhängigkeitsverhältnis zwischen dem KU und der Vielzahl verschiedener Redeformen (eine Ausnahme ist der Textabschluß - Sätże 200-204 vgl. die Erklärung oben).

Dasselbe gilt hauptsächlich auch für syntaktische Erscheinungen und verschiedene Stileme. Allgemein zeigt sich im Text ein variationsreicher Gebrauch zahlreicher syntaktischer Ausdrucksmittel mit zunehmender Tendenz in den bereits oben besprochenen, kommunikativ exponierten Knotenpunkten. Unverkennbar tritt das hervor z. B. im Textabschnitt 124-127 (mit dem KU 10,17), wo trotz relativer 
Kürze (insgesamt nur 59 Wörter) 9 verschiedene syntaktische Strukturen und verschiedene Stileme nebeneinander für die Lockerheit im Ausdruck sorgen. Noch überzeugender ist das in der Passage 147-160 (12 syntaktische Besonderheiten) und in der Passage 161-189 (mit 11 verschiedenen syntaktischen Besonderheiten).

Ein Vergleich mit anderen Teiltexten (z. B. 90-98, 115-123, 128-146) bekräftigt die obige Begründung. In Sätzen 200-204 ist allerdings die schlichte Syntax (3 kurze Einfachsätze) ein Kontrast zur Gesprächigkeit im Vortext, was die Dynamik des gesamten Erzählens steigert. Damit stimmen auch die verwendeten Rededarstellungsformen überein (in Sätzen 200-204 ausschließlich Erzählerrede). Die für den relativ kurzen Textabschnitt sehr dicht gebrauchte umgangssprachliche Lexik (KU 10,53) dient jedoch einer intensiven Emotionalisierung der Schlußerkenntnisse, die in eindeutig negativ wertenden Tönen gefärbt sind.

Daraus ist zu folgern, daß in den Textsegmenten mit einem größeren KU eine innere, mit Faktoren und Bedingungen der Kommunikation zusammenhängende Dynamik den Einsatz verschiedener anderer Ausdrucksmöglichkeiten bedingt, die u. a. die Anschaulichkeit und Spontaneität hervorrufen helfen.

\subsection{Kommunikative Funktionen umgangssprachlicher Ausdrucksmittel - Klassifikation}

Die oben festgestellten Korrelationen sind offenbar funktional bedingt. Das bedeutet, daß umgangssprachliche Ausdruckselemente in der schriftlichen Kommunikation hauptsächlich bewußt eingesetzt werden, um gewissen kommunikativen Zwecken in gewissen Textpassagen zu dienen. Die qualitative Analyse der Streuung umgangssprachlicher Ausdruckselemente im Text hat gezeigt, daß an gewissen "kritischen" Knotenpunkten im Textgeschehen die subjektive Anteilnahme des am Ereignis Beteiligten besonders intensiv zu sein scheint und daß sich an diesen Stellen der Textproduzent intensiver als anderswo der umgangssprăchlichen Ausdruckselemente bedient (vgl. HEUSINGER 1986: 320). Umgangssprachliche Elemente wirken sich hier wie ein optisches Instrument, wie ein Prisma aus, in dem die schwarz-weiße Realität als Gegenstand der Versprachlichung je nach Einstellung des Senders subjektiv gebrochen wird. Damit werden in Übereinstimmung mit der Kommunikationsabsicht, dem Kommunikationsplan, der kommunikativen Situation und mit anderen kommunikativen Determinanten in die Wiedergabe der Realität (mehr oder weniger bewußt) verschiedene Farbtöne gebracht. Das ist die Grundlage, aus der ich verschiedene kommunikative Funktionen umgangssprachlicher Ausdruckselemente ableite.

Kommunikative Funktionen umgangssprachlicher Ausdrucksmittel sind ähnlich wie kommunikative Textfunktionen klassifizierbar, weil sie aus diesen logischerweise hervorgehen. Ich unterscheide mittelbare und unmittelbare kommunikative Funktionen umgangssprachlicher Ausdrucksmittel; letztere werden in allgemeine, besondere und absolute (vorwiegend (kon)textunabhängige) unterteilt. Besondere kommunikative Funktionen sind in thematischer, gegenständlicher und psycho-sozialer Hinsicht für einen bestimmten Text bzw. für eine bestimmte Textsorte spezifisch, die 
sog. "absoluten" sind dagegen sprachsystemgebunden und sind nicht auf den jeweiligen Text angewiesen. An dieses Grundgerüst lehnt sich eine ausführlichere Differenzierung kommunikativer Funktionen umgangssprachlicher Ausdrucksmittel an, die jedoch nicht starr aufgefaßt werden darf, denn das System muß im Prinzip offen sein, und es muß Ergänzungen, Verbesserungen und andere Veränderungen zulassen. (Vgl. Tabelle V.)

Zusammenfassend könnte man sagen, daß die umgangssprachlichen Ausdrucksmittel im vorliegenden Mustertext in erster Linie zu dem Zweck verwendet sind, die möglichen Bedenken anläßlich des fragwürdigen Unternehmens der alten Dame abzuschärfen, eine bildhafte, spielerische und geistreiche Stimmung auf der Reise vorzuzaubern, die beim Leser die Überzeugung stärken soll, daß es sich nicht um eine Leichtsinnige handelt, die nur auf billige Abenteuer aus ist, sondern um eine unternehmungslustige jugendliche, in moralischer Hinsicht allerdings einwandfreie Pensionierte.

Tabelle V: Kommunikative Funktionen umgangssprachlicher Ausdrucksmittel

MITTELBARE (Realisierung der Textfunktion)

UNMITTELBARE:

allgemeine (Realisierung von FKM der KV)

besondere (thematisch-psycho-soziale):

grundlegende: abgeleitete:

Inoffizialität ... Kontaktaufnahme

(modifizierte)

Bildhaftigkeit ... Kontaktvertiefung

subjektive emotionelle

Einstellung Anschaulichkeit Unmittelbarkeit

absolute (systemgebundene):

Beunruhigung ...

Identifizierung

Distanzierung

Eröffnen und Schließen des Textrahmens

Sprachporträt - Charakterisierung der Person

idiolektale Inertion

Isotopieketten

Ausfüllen von Lücken im Sprachsystem

häufig verwendete Ausdrucksmittel

Zwischen den kommunikativen Funktionen umgangssprachlicher Ausdrucksmittel gibt es keine scharfen Grenzen, viele sind untereinander verwandt. Einige sind dominant und können gleichzeitig mit den begleitenden auftreten; die dominanten müssen jedoch nicht unbedingt auch die häufigsten sein. Dasselbe umgangssprachliche Ausdrucksmittel kann in verschiedenen Kontexten verschiedene kommunikative Funktionen erfüllen. Wiederholtes gleichzeitiges Auftreten mehrerer 
kommunikativer Funktionen umgangssprachlicher Ausdrucksmittel führt zur Funktionsbündelung. Einige kommunikative Funktionen können die Realisierung anderer kommunikativer Funktionen auslösen. Die Kriterien zur Bestimmung kommunikativer Funktionen umgangssprachlicher Ausdrucksmittel sind sowohl subjektiver (Intuition) als auch objektiver Natur. Darin spiegelt sich auch eine wichtige Rolle der Rezipientenperspektive wider (vgl. 2.).

\section{VERGLEICHENDE ANALYSE}

Die vergleichende Analyse der acht Reiseerzählungen (Textsorte als Konstante!) hat hauptsächlich die Ergebnisse der Mustertextanalyse bestätigt und einige zusätzliche Erkenntnisse erbracht (vgl. auch Tabelle VI):

Der KU und die mittlere Satzlänge sind im Korpus signifikant umgekehrt proportional. Daraus folgert die wichtige Feststellung, daß sich syntaktische Strukturen gewissermaßen dem Grad der Umgangssprachlichkeit in einem Text "anpassen" und daß es somit legitim ist, im Rahmen bekannter Einschränkungen (vgl. 5.3.) von einer (mehr oder weniger) umgangssprachlichen Syntax sprechen zu dürfen.

Die Situationsebene der Erzählung herrscht ausdrücklich vor der Handlungsebene vor. Diese Behauptung kann aufgestellt werden, obwohl sie auf einer empirischen Einschränkung beruht, daß zu dieser Analyse nur die Sätze herangezogen wurden, die umgangssprachliche Ausdrucksmittel enthalten. Diese empirische Einschränkung bekräftigt zugleich die Gültigkeit der Hypothese, daß umangssprachliche Ausdrucksmittel vorwiegend im Zusammenhang mit dem subjektiven Verhältnis des Erzählers zu der zu versprachlichenden Wirklichkeit vorkommen, das hauptsächlich auf der Situationsebene der Erzählung realisiert wird.

Bezüglich der Rededarstellungsformen herrscht ausdrücklich die Erzählerrede vor.

Die erzählende Person in der modernen Erzählung ist die 1. Person.

Das typische Erzähltempus ist das Präsens, und nicht das Präteritum, wie es bis vor kurzem eine verbreitete Meinung war. Pragmatisch interessant sind Kombinationen, wo der Text mit dem Präteritum beginnt, um dann an entsprechender Stelle ins Erzählen im Präsens überzugehen (vgl. Tabelle VI). ${ }^{<51>}$

Hinsichtlich der kommunikativen Funktionen umgangssprachlicher Ausdrucksmittel kann festgestellt werden, da $\boldsymbol{B}$ die in der Mustertextanalyse erstellte Klassifikation einer Nachprüfung in den vergleichenden Analysen völlig standhalten kann.

Es wurde auch bestätigt, daß die Klassifikation kommunikativer Funktionen umgangssprachlicher Ausdrucksmittel aus der Mustertextanalyse ein offenes System darstellt, denn es sind zusätzliche kommunikative Funktionen umgangssprachlicher Ausdruckselemente zu denjenigen möglich, die in der Mustertextanalyse herausgefunden wurden. 
Tabelle VI: Übersichtsdarstellung einiger Parameter der vergleichenden Analyse

\begin{tabular}{|c|c|c|c|c|c|}
\hline sprachliche & KU & MSL & SE:HE & RF & $\mathbf{P}$ \\
\hline Besonder- & 4,29 & 11,9 & $62: 9$ & 48 ER & 1 \\
\hline heiten & & & & $7 \mathrm{DR}$ & \\
\hline Text & & & & $5 \mathrm{IR}$ & \\
\hline I & & & & 8 FBER & \\
\hline & & & & 8 IM & \\
\hline & & & & $2 \mathrm{erRe}$ & \\
\hline & & & & 1 erRf & \\
\hline
\end{tabular}

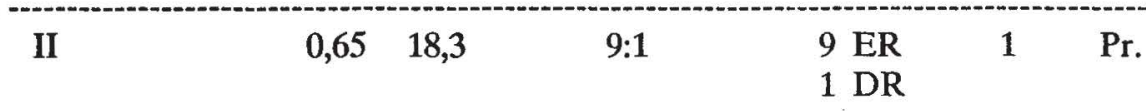

\begin{tabular}{|c|c|c|c|c|c|c|}
\hline III & $\begin{array}{c}0,82 \\
(0,98)\end{array}$ & $\begin{array}{c}16,6 \\
(16,2)\end{array}$ & $5: 4$ & $\begin{array}{ll}6 & \text { ER } \\
1 & \text { FBER } \\
1 & \text { IM } \\
1 & \text { DR }\end{array}$ & 1 & $\mathbf{P}$ \\
\hline IV & 1,13 & 15,9 & $8: 3$ & $\begin{array}{r}10 \mathrm{ER} \\
1 \mathrm{DR}\end{array}$ & 1 & $\mathrm{P}$ \\
\hline V & 0,66 & 18,7 & $6: 2$ & $\begin{array}{l}7 \mathrm{ER} \\
1 \mathrm{IR}\end{array}$ & 1 & $\mathbf{P}$ \\
\hline VI & 2,00 & 9,3 & $31: 5$ & $\begin{array}{r}32 \mathrm{ER} \\
4 \mathrm{DR}\end{array}$ & 1 & $\mathrm{Pr} . \rightarrow \mathrm{P}$ \\
\hline VII & $\begin{array}{c}2,17 \\
(3,63)\end{array}$ & $\begin{array}{c}11,9 \\
(11,9)\end{array}$ & $11: 4$ & $\begin{array}{r}12 \mathrm{ER} \\
3 \mathrm{DR}\end{array}$ & 1 & Pr. $\rightarrow P$ \\
\hline VIII & 1,59 & 13,9 & $15: 6$ & $21 \mathrm{ER}$ & 1 & $\mathbf{P}$ \\
\hline IX & 1,14 & 14,4 & $6: 8$ & $14 \mathrm{ER}$ & 1 & $\mathbf{P}$ \\
\hline
\end{tabular}

Legende: KU -

MSL -

SE:HE -

RF -

P -

T -

ER -

DR -

FBER -
Koeffizient der Umgangssprachlichkeit mittlere Satzlänge (Wortanzahl)

Situationsebene vs. Handlungsebene der Erzählung Rededarstellungsform

Person

Tempus

Erzählerrede direkte Rede

figurenbeeinflußte

Erzählerrede
IM - innerer Monolog

IR - indirekte Rede

erRe - erlebte Rede erRf - erlebte Reflexion

P - Präsens

Pr. - Präteritum 


\section{ABSCHLIEßENDE BEMERKUNGEN}

Gegenstand dieser Untersuchung war die Verwendung umgangssprachlicher Elemente in der geschriebenen Sprache, und nicht etwa in der gesprochenen Sprache, in der die Umgangssprache als Varietät ihren normativen Status hat und ihr Gebrauch vom Hörer erwartet wird (vgl. SANDIG 1986: 34). In der "Schriftlichkeit" wirken umgangssprachliche Ausdruckselemente nach wie vor mehr oder weniger expressiv. Aus dem spezifischen Zusammenhang der kommunikativen Determinanten in der untersuchten Pressereiserzählung (psycho-physiche Eigenschaften des Senders, Reise per Anhalter, unbekannte Leserschaft), insbesondere noch aus der Phasenverschiebung zwischen der primären und sekundären kommunikativen Situation resultieren jene Kodierungsbedingungen, die die Strategie bei der Textgestaltung mitgeprägt haben. Der Einsatz umgangsprachlicher Ausdrucksmittel im Text erweist sich dabei als funktional bedingt. In der kommunikativen Optik stellen verschiedene Winkel, in denen sich die Strahlen im Prisma der Umgangssprachlichkeit brechen, verschiedene kommunikative Funktionen umgangssprachlicher Ausdrucksmittel dar.

Somit werden in der vorliegenden Untersuchung Fragen angeschnitten, die nicht nur mit dem Sprachsystem zusammenhängen, sondern die sich vor allem auf die Bewußtmachung kompetenter Verwendung von Variationsmöglichkeiten der Sprache in verschiedenen kommunikativen Situationen beziehen.

\section{Anmerkungen}

<1>DIMTER (1981: 86) unterscheidet im Text Endziele und Instrumentalziele sowie hypotaktische und parataktische Beziehungen zwischen ihnen. Damit ebnet er den Weg der Verständigung von funktional bedingten Teiltexten in einem Text.

<2> BRINKER (1983: 142) spricht von der signalisierten (direkten) und von der tatsächlichen (indirekten) Textfunktion.

<3> Direkte Bedeutung einer Mitteilung kann eine direkte Rezeption und eine begleitende (Neben)rezeption auslösen. Im 1. Fall geht es um das übliche Kommunikationsereignis, im 2. Fall um eine künstlerisch-ästhetische Wirkung, z. B. in einer künstlerischen Interpretation eines Textes. Des öfteren gehen aber m. E. die direkte und indirekte begleitende Rezeption mit versteckter (indirekt ausgedrückter) Bedeutung einer Mitteilung einher. Im ersten Fall ist somit wohl eine Art Manipulation vorhanden, im zweiten dagegen das Entlarven. (Vgl. HARNISCH 1983: 53.)

$<4>$ "Derselbe Text(ausschnitt) kann also auf verschiedene Rezipienten sehr verschieden wirken" (SANDIG 1986: 92).

$<5$ HARTUNG definiert sie als "systemhafte und im Sprecherbewußtsein verankerte Manifestationen einer 'abstrakten Sprache', nicht notwendigerweise Modifikationen oder Varianten einer 'konkreten Sprache" (HARTUNGSCHÖNFELD 1981: 76). Für NABRINGS (1981: 137) sind Varietäten sozial verbindliche, für jede Sprache typische Realisationsmuster einer Sprache.

<6> Die Varietäten werden hauptsächlich nach drei Gesichtspunkten gegliedert 
(sozial, territorial, funktional). Besonders interessant ist aber auch ein vierter Gesichtspunkt, die Realisationsweise (schriftlich - mündlich), der sich maßgeblich auf die Kodierungsbedingungen auswirkt.

<7> Zwischen den einzelnen Varietätenarten einer Sprache herrschen Korrelationsbeziehungen (vgl. HARTUNG-SCHÖNFELD 1981: 95 und WIESINGER 1985: 1940). Der soziale Aspekt ist z. B. auch vorhanden, wenn man von der Realisationsweise, von der territorialen und der funktionalen Gliederung der Sprache spricht. Fach- bzw. Berufssprachen können mit Elementen der Interessensprachen durchsetzt sein ("Berufsjargonismen"), von denen sich die Wissenschaftssprache mehr oder weniger distanziert.

<8> Vgl. HARTUNG (1977: 67), BETTEN (1985: 80), BERTHOLD (1968: 336), SPERLBAUM (1975: 126), aber auch STEGER (1984: 251, 267).

<9> Unmarkiert ist die Umgangssprache als Schriftsprache jedoch im Privatverkehr (Briefwechsel u.ä.) und sogar dann, wenn protokollierte mündliche Äußerungen als Figurenrede in der Belletristik vorliegen (zumeist Dialoge).

$<10>$ Intentionale Determinanten des Kommunikationsereignisses sind nicht immer explizit bei der Kommunikation im Kommunikationsbereich der Kunst und des (intimen) Privatlebens vorhanden.

<11> Auseinanderzuhalten sind die Begriffe stoffliche Basis, Kommunikationsgegenstand, Kommunikationsthema, Inhalt. Aus allem, was erlebt wurde (stoffliche Basis), werden nur ausgewählte Erlebnisse (Kommunikationsgegenstand) als roter Faden, d. h. unter einem besonderen Blickwinkel (Kommunikationsthema) festgehalten. "Mit 'Inhalt' erfassen wir den KG (Kommunikationsgegenstand; S. B.) als einen Teil 'subjektiv angeeigneter Wirklichkeit" (HEUSINGER 1984: 96).

<12> Mit römischen Ziffern bezeichne ich im weiteren Absätze, mit arabischen Sätze; Buchstaben (Groß- und Klein-) sind für (größere und kleinere) gedankliche Einheiten verwendet.

$<13>$ Satz 15 ist eine Art Übergang zu Abschnitt A1,2.

$<14>$ Und zugleich Retardation.

$<15>$ Zu den Beziehungen zwischen dem ersten Satz im Text, der Überschrift und der Rhematizität der beiden Elemente siehe in EROMS (1986: 87).

$<16>$ Merke die Steigerung der abwertenden konnotativen Dimension!

$<17>$ Darin sind Ansätze zu einer funktionalen Textperspektive zu sehen.

$<18>$ Vgl. zum "Neben- und Miteinander einzelner Kommunikationsverfahren" (SCHMIDT et al. 1981: 163). An mehreren Stellen schlägt z. B. im Teiltext C (115-199) (gefährliche Ereignisse auf der Rückreise) das Mitteilen (wegen der Intensität im Erleben und der stark emotionellen Reaktionen der Erzählerin) ins Schildern um, so daß einzelne Teiltexte hier eben Schilderungen sind. Das 
konstitutive (inventive) KV Beurteilen (in Sätzen 200-204) könnte als Ganzes auch gewisse inzitative Elemente der FKM im Sinne von Warnung, Abraten enthalten (vgl. SCHMIDT et al. 1981: 27, 160 f.; vgl. auch zur rezeptiven Komponente der kommunikativen Funktion in 2.c).

<19> So leuchtet es ein, daß KV gegenüber den statischer aufgefaßten Sprechakten sich durch eine größere Operationalisierbarkeit auszeichnen. (Vgl. MICHEL 1982.)

$<20>$ In unserem Mustertext werden mit dem Fragen u. a. noch folgende KV verwirklicht: das Anregen (Satz 1), das Interjektieren (Satz 12; vgl. Anm. ${ }^{<23>}$ ), das Beurteilen (Satz 32), das Appellieren (Satz 42).

$<21>$ So ist z. B. das Feststellen als KV nur im Präsens oder Perfekt möglich (vgl. Satz 82). Dieselbe Prädikation im Präteritum wirkt als Mitteilen. Durch die Tempusveränderung wird also ein KV derselben Prädikation in ein anderes KV umfunktioniert. Das Feststellen im Präsens (in geringerem Ausmaß jedoch im Perfekt wegen der Zeitdistanz als pragmatisches Parameter) kann aber nur als Behaupten klassifiziert werden, wenn der Sprecher/Schreiber nicht über genügend Beweise für eine Feststellung verfügt (vgl. Satz 112 sowie SCHMIDT et al. 1977: 156).

$<22>$ Beispielsweise könnte man unter Beachtung der Position des Satzes 26 im Text (rahmenschließender Satz - Teiltext $A_{1,1}-A_{1,3}$, insbesondere seine logische Bezogenheit auf den Vordersatz 25) dem darin durchgeführten KV Schildern auch charakteristische Merkmale des Explizierens zuschreiben.

<23 Bei diesem semantisch leeren KV gibt es keine "Zweckbestimmtheit als ein grundlegendes Merkmal von Kommunikationsverfahren" (HARNISCH 1983: 46).

Typische FKM dieses KV wären: 'emotional erleichternd', 'spontan', 'bedeutungsleer'. Durch dieses KV wird ein Sich-Abfinden mit der konkreten Sachlage artikuliert. (Vgl. Entlastung oder Stabilisierung des psychischen Haushalts des Sprechers als eine der Textfunktionen bei SCHMIDT 1982: 14.)

$<24>$ Die Bestimmung der figurenbeeinflußten Erzählerrede ist z. B. in Satz 163 durch die Position des Satzes im Kontext erleichtert: voran- und nachgestllt (Sätze 162 und 164) ist direkte Rede.

<25> Das Wesen der figurenbeeinflußten Erzählerrede kann mit Hilfe eines Satzvergleiches veranschaulicht werden. Sätze 21 und 41 (aus dem Mustertext) stellen nach meiner Ansicht die figurenbeeinflußte Erzählerrede dar. Satz 21 ist aus 2 Teilsätzen zusammengesetzt, der 2. Teilsatz enthält das KV Begründen in bezug auf das KV Feststellen im 1. Teilsatz (vgl. SCHMIDT et al. 1981: 35, 147). Das KV Begründen in bezug auf das KV Feststellen in Satz 41 ist aber in Satz 42 in direkter Rede ausgedrückt. Das in beiden Fällen logischerweise von der Figur ausgehende Begründen ist in beiden, syntaktisch parallelen Konstruktionen also unmittelbar auf das KV Feststellen bezogen, wobei es einmal in direkter Rede ausgedrückt ist (Satz 42), in Satz 21 aber in ihrer Modifikation, in der sog. figurenbeeinflußten Erzählerrede. Das dürfte als ein Beweis dafür gelten, daß die 
Rededarstellungsform in Satz 21 nicht schlechthin mit der herkömmlichen Erzählerrede identisch ist.

$<26>$ Darüber hinaus war für die Untersuchung von großer Bedeutung die Feststellung (bestätigt auch in der vergleichenden Analyse), daß umgangssprachliche Ausdrucksmittel nicht nur in der direkten Rede oder z. B. im inneren Monolog vorkommt, also nicht nur in jenen Rededarstellungsformen, in denen sie in erster Linie dem sprachlichen Porträtieren der Figuren oder der Protokollierung bereits erlebter Sprechsituationen dienen, sondern gleichermaßen auch in der Erzählerrede, was als ein Beweis dafür gelten mag, daß Umgangssprache auch dort in den schriftlichen Kode eindringt, wo sie auf den ersten Blick in bezug auf traditionelle Vorstellungen nicht erwartet würde.

<27> Vgl. DIMTER (1981: 24) und seine "dominante Textfunktion"; BRINKER (1983: 136) und GÜLICH-HEGER-RAIBLE (1979: 13) sprechen von der "anaphorischen und kataphorischen Signemfunktion", d.i. von der anaphorischen und kataphorischen Teiltextfunktion.

<28> Vgl. DIMTER (1981: 69) und seine "indirekten" Sprechakte zur Verfolgung anderer Ziele sowie VIEHWEGER (1984: 93) und seine "primären Handlungsziele". Davon sind zu unterscheiden die textinternen Funktionen von Teiltexten (z. B. Einleitung), die von DIMTER außer den durch Sprecherziele bestimmbaren Teiltextfunktionen erwähnt werden (1981: 85).

$<29>$ Vgl. bei DIMTER (1981: 74 ff.) zu hypotaktischen und parataktischen Zielbeziehungen.

<30> SANDIG (1986: 72) sieht einen Zusammenhang zwischen der Stilwirkung beim Rezipienten und dem "gemeinsamen Wissen".

<31> Vgl. zur Vagheit konnotativer Inhalte auf der Wortebene bei. SORNIG (1981:

86). Auf der Textebene ist jedoch die konnotative Textpotenz für LERCHNER (1984: 44 u. passim) ein Funktionspotential.

<32> Vgl. zur. Unterscheidung von Begriffen Bedeutsamkeit und Sinn bei BIEBERLE (1987: 199 f.).

<33> Für BRINKER (1983: 145) sind Textsorten konventionalisierte Muster für komplexe sprachliche Handlungen.

<34> Vgl. den Terminus "Erlebniserzählung" bei HEUSINGER (1984: 105, Anhang: $45 \mathrm{f}$.$) .$

<35> STEWART (1978: 483 ff.) spricht beim Reisebericht von pragmatischen Dimensionen des Untersuchungsgegenstands und in diesem Zusammenhang von verschiedenen Wirkungen auf den Leser: pädagogischer, politisch-sozialkritischer u.a.m. Interessant wäre auch die Abgrenzung von der Textsorte Reportage.

<36> Der Oberbegriff Reisedarstellungen läßt sich m. E. trotz Einwänden von THIELE (1983: 356), daß die Typologisierung der Texte in Textklassen, Texttypen, Textarten und Textsorten "im einzelnen sicher nur schwer 
operationalisiert werden kann", relativ gut folgendermaßen untergliedern: Die geläufige Bezeichnung "Reisebericht" trifft im engeren Sinne des Wortes nur für solche Textarten zu, die sachbetont mitteilen, wie die Geschehnisse auf einer Reise vor sich gingen. Solche Texte sind relativ schwer zu finden, das könnte $\mathrm{m}$. E. allerdings ein faktographisch geführtes (Dienst)tagebuch einer Schiffahrt sein. "Reisebeschreibung" wäre gemäß den oben angeführten theoretischen Prämissen jene Textart, die sachbetont Zustände oder Gegenstände ( "Landschafts-beschreibungen") beschreibt oder aber agensabgewandte wiederholte und wiederholbare Vorgänge (vgl. SCHMIDT et al. 1981: 103). Das könnte z. B. die Wegbeschreibung in einem touristischen Reiseführer sein. "Reiseerzählung" ist jene Textart, die erlebnisbetont Ereignisse auf einer Reise darstellt (s. mehr dazu weiter unten).

"Reiseschilderung" ist die Textart, die vor allem erlebnisbetont, unmittelbar und spontan die sich beim Textproduzenten einstellenden Eindrücke und Stimmungen beim Erleben der Natur oder der Ereignisse auf einer Reise vermittelt. Dabei ist nicht wesentlich unterschiedlich, ob diese Eindrücke unmittelbar nach dem Erleben fixiert werden oder aber der Autor sie nach Erinnerung vermittelt. Hinzuweisen ist noch darauf, daß Reiseschilderungen selten selbständige Texte sind. Hauptsächlich sind sie Bestandteile anderer Texte, des öfteren der Erzählungen.

$<37>$ Der Strichpunkt trennt das formale KV von dem tatsächlichen ab.

$<38>$ Bei der Angabe der FKM sind hier und im weiteren die allgemeinen, für das jeweilige KV wesentlichen FKM gemeint.

<39> Ersparung eines prädikativen Beiwortes (vgl. SPERLBAUM 1975: 25).

$<40>$ Es handelt sich um Sprecherleichterungen und Verschleifungen, die unter dem Einfluß der Schnellsprechregeln entstehen (vgl. LÖFFLER 1985: 95 und BETTEN 1985: 244).

$<41>$ Die beiden uneingeleiteten Nebensätze "er dürfe sowieso niemanden mitnehmen" und "tanken muß er auch" implizieren auf der elementaren, d.i. auf der III. Kommunikationsebene ein Begründen bezüglich der konklusiven Prädikation "da kann ich raus".

<42> "Da" weist unstabile Umgangssprachlichkeit auf. Nach den Wörterbüchern KEMPCKE et al. (1984), BROCKHAUS WAHRIG (1980-1984), DUDEN (1977-1981), KÜPPER (1982-1984) ist "da" stilistisch neutral. KLAPPENBACHSTEINITZ (1967-1977) und WAHRIG (1986/87) behandeln es differenzierter und empfinden es $u$. U. als umgangssprachliches Lexem. Umgangssprachlich ist nicht das Wort an sich, sondern dessen Einsatz als Korrelat, das aufgrund einer erfüllten Bedingung (tanken müssen) die Folge davon ankündigt (rauskönnen). In unserem Mustertext ist die Partikel "da" häufig nachweisbar (sie drückt vielmehr einen Umstand, eine Situation aus als Ort oder Zeit) und bildet - wenn der Text als Ganzes betrachtet wird - eine Anapherkette.

<43> Vgl. NELLEN (1986: 119), nach welchem der Schlußsatz den Leser amüsieren, verblüffen, verwundern soll. 
$<44>$ Wenn wir alle lexischen und morphologischen umgangssprachlichen Ausdrucksmittel in einem Text zusammenziehen und die Summe mit der Gesamtzahl der Wörter in diesem Text vergleichen, erhalten wir den Koeffizienten der Umgangssprachlichkeit (KU) dieses Textes. Dieser KU veranschaulicht die umgangssprachliche Dichte in einem Text. Da in diesem Untersuchungstest dieses Verhältnis 105: 2446 beträgt, ist der $\mathrm{KU}$ 4,29; das bedeutet, daß auf alle 23 Wörter im Text eine lexikalische oder morphologische umgangssprachliche Besonderheit kommt.

$<45>$ Auch WIESINGER bestätigt diese Tatsache: "Auf der syntaktischen Ebene neigt man heute dazu, Umgangssprachliches auch schriftsprachlich zu akzeptieren (1985: 1943).

$<46>$ Es stellt sich heraus, daß dieser Untersuchungstext im Durchschnitt kürzere Sätze aufweist als die Untersuchungskorpora bei EGGERS (1962) und BERTHOLD (1968). (Vgl. auch die Ergebnisse der Untersuchungen von HÖHNELESKA (1975). (Vgl. auch LÜGER 1983: 24.)

Zur Überprüfung der Geltung der sich im gegenwärtigen Deutsch abzeichnenden Tendenz, nach welcher die Sätze kürzer würden und der Einfachsatz zunehme (vgl. RATH 1985: 1653), wäre ein Vergleich mit anderen Textsorten aus der Presse interessant, insbesondere unter Beachtung der Feststellung aus dem Jahr 1968, daß "die Sprache der Presse mit dem leichten Übergewicht hypotaktischer Fügungen ... noch stärker der schriftsprachlichen Tradition verhaftet /ist/, die das Gefüge bevorzugte ... " (BERTHOLD 1968: 79). Als Ausgangspunkt für eine solche vergleichende Studie könnte auch die Angabe dienen, daß in meinem Mustertext der Prozentsatz der Parataxen und der Einfachsätze gleich ist (also $37,75 \%$ oder 77 von den 204 Sätzen), Hypotaxen sind aber weniger $(24,50 \%$ oder 50 von den 204 Sätzen). Daß Parataxen vor den Hypotaxen überwiegen, stimmt mit den allgemeinen Charakteristiken der Umgangssprache überein.

$<47>$ Der Koeffizient der Umgangssprachlichkeit hat hier als ein mögliches Kriterium zur Textsegmentierung gedient.

$<48>$ Vgl. mit den "Spannungsbögen" in Kapitel 4.

<49> Hiermit bestätigt sich die These, daß syntaktische Strukturen vorwiegend nicht an sich umgangssprachlich seien, sondern daß vielmehr ihre Häufigkeit und ihre typische Verteilung im Text, der eine (sprachliche) Widerspiegelung eines Kommunikationsereignisses ist, in der Tendenz ihre Umgangssprachlichkeit herbeiführen können.

$<50>$ Eine Nebenuntersuchung hat ergeben, daß die häufigsten vier kommunikativen Funktionen der umgangssprachlichen Elemente im Text der Reihe nach Distanzierung, idiolektale Inertion, Identifizierung und Charakterisierung der Figur sind. Dabei überwiegen interessanterweise Identifizierungen am Textbeginn, Distanzierungen nehmen jedoch gegen Ende des Textes zu.

$<51>$ Das einzige ausschließliche Präteritum befindet sich wahrscheinlich nicht durch Zufall eben im Text mit dem niedrigsten Umgangssprachlichkeitskoeffizienten (Text II). 


\section{Auswahlbibliographie}

AGRICOLA Erhard (1977): Textstruktur aus linguistischer Sicht. In: Wort-SatzText, Ausgewählte Beiträge zur Sprachwissenschaft. Leipzig, S. 244-249. (Germanistische Studientexte)

BEAUGRANDE Robert-Alain de - DRESSLER Wolfgang Ulrich (1981): Einführung in die Textlinguistik. Tübingen. (Konzepte der Sprach- und Literaturwissenschaft; 28)

BERTHOLD Hans (1968): Zur Syntax der ostmitteldeutschen monologischen gehobenen Umgangssprache. Als Promotionsschrift bei der HistorischPhilologischen Fakultät der Pädagogischen Hochschule Potsdam.

Dissertation, maschinenschriftlich.

BETTEN Anne (1985): Sprachrealismus im deutschen Drama der siebziger Jahre. Heidelberg.

BIEBERLE Bruno (1987): Zum Erschließen des Sinns von Texten. In: Deutschunterricht, 40, S. 198-203.

BRINKER Klaus (1983): Textfunktionen. Ansätze zu ihrer Beschreibung. In: Zeitschrift für germanistische Linguistik, 11.2, S. 127-148.

BROCKHAUS WAHRIG (1980-1984): Deutsches Wörterbuch in sechs Bänden. Wiesbaden, Stuttgart.

DIMTER Matthias (1981): Textklassenkonzepte heutiger Alltagssprache. Kommunikationssituation, Textfunktion und Textinhalt als Kategorien alltagssprachlicher Textklassifikation. Tübingen. (Reihe Germanistische Linguistik; 32)

DUDEN (1973 ${ }^{17}$ ): Der Große Duden in 10 Bänden. Band 1: Rechtschreibung der deutschen Sprache und der Fremdwörter. Mannheim.

DUDEN (1977-1981): Das große Wörterbuch der deutschen Sprache in 6 Bänden. Mannheim, Wien, Zürich.

EGGERS Hans (1962): Zur Syntax der deutschen Sprache der Gegenwart. In: Studium generale, 15, 1, S. 49-59.

EROMS Hans-Werner (1986): Funktionale Satzperspektive. Tübingen. (Germanistische Arbeitshefte; 31)

FLEISCHER Wolfgang - MICHEL Georg $\left(1977^{2}\right)$ : Stilistik der deutschen Gegenwartssprache. Leipzig.

GROSSE Rudolf - NEUBERT Albrecht (1982): Soziolinguistische Aspekte der Theorie des Sprachwandels. Berlin. (Sitzungsberichte der Akademie der Wissenschaften der DDR. Gesellschaftswissenschaften; 106)

GÜLICH Elisabeth - HEGER Klaus - RAIBLE Wolfgang $\left(1979^{2}\right)$ : Linguistische 
Textanalyse. Überlegungen zur Gliederung von Texten. Hamburg. (Papiere zur Textlinguistik; 8)

HARNISCH Hanna (1983): Zum Wesen von Kommunikationsverfahren (KV). In: Potsdamer Forschungen, Reihe A, 57, S. 41-54.

HARTUNG Wolfdietrich (1977): Zum Inhalt des Normbegriffs in der Linguistik. In: Normen in der sprachlichen Kommunikation. Berlin, S. 9-69. (Reihe Sprache und Gesellschaft; 11)

HARTUNG Wolfdietrich - SCHÖNFELD Helmut et al. (1981): Kommunikation und Sprachvariation. Berlin.

HELBIG Gerhard (1986): Entwicklung der Sprachwissenschaft seit 1970. Leipzig.

HENNIG Jörg - HUTH Lutz (1975): Kommunikation als Problem der Linguistik. Eine Einführung. Göttingen.

HEUSINGER Siegfried (1981): Zum ontogenetischen Aspekt einer funktional-kommunikativen Beschreibung von Schülertexten. In: Wissenschaftliche Zeitschrift der Pädagogischen Hochschule "Erich Weinert" Magdeburg, 18, 6, S. 546-560.

HEUSINGER Siegfried (1984): Kommunikations- und sprachtheoretische Positionen zum ontogenetischen Aspekt der Textgestaltung. Magdeburg. Dissertation, maschinenschriftlich.

HEUSINGER Siegfried (1986): Kommunikative Adäquatheit oder kommunikative Angemessenheit? In: Zeitschrift für Germanistik, 7, 3, S. 318-321.

HEUSINGER Siegfried (1987): Zum Erfassen der Textfunktion durch den Rezipienten. In: Wissenschaftliche Zeitschrift der Pädagogischen Hochschule "Karl Liebknecht" Potsdam, 31, 5, S. 885-889.

HEUSINGER Siegfried (1987a): Zur Tiefe des Verstehens. In: Deutschunterricht, 40, 4, S. 193-198.

HÖHNE-LESKA Christel (1975): Statistische Untersuchungen zur Syntax gesprochener und geschriebener deutscher Gegenwartssprache. Berlin. (Abhandlungen der Sächsischen Akademie der Wissenschaften zu Leipzig. Philologisch-historische Klasse; 59)

KAEMPFERT Manfred (1985): Die Entwicklung der Sprache der deutschen Literatur in neuhochdeutscher Zeit. In: Werner Besch-Oskar Reichmann-Stefan Sonderegger, Hg., Sprachgeschichte, Ein Handbuch zur Geschichte der deutschen Sprache und ihrer Erforschung. Berlin-New York, 2, S. 1810-1837.

KEMPCKE Günter et al. (1984): Handwörterbuch der deutschen Gegenwartssprache. In zwei Bänden. Berlin.

KLAPPENBACH Ruth - STEINITZ Wolfgang, Hg. (1967-1977): Wörterbuch der deutschen Gegenwartssprache. Berlin. 
KUPPER Heinz (1982-1984): Illustriertes Lexikon der deutschen Umgangssprache in , 8 Bänden. Stuttgart.

LANGNER Helmut (1986): Zu einigen Ergebnissen und Problemen des Einflusses der Umgangssprache auf die Literatursprache (Schriftsprache) der Gegenwart. In: Bernd Wilhelmi, Hg., Umganssprachen und Dialekte in der DDR, S. 100-113. (Wissenschaftliche Beiträge der Friedrich-Schiller-Universität Jena)

LERCHNER Gotthard (1984): Konnotative Textpotenz. In: Beiträge zur Erforschung der deutschen Sprache, 4, S. 39-48.

LÖFFLER Heinrich (1985): Germanistische Soziolinguistik. Berlin. (Grundlagen der Germanistik; 28)

LÖSCH Wolfgang (1986): Merkmale der regionalen Umgangssprache in Südthüringen. In: Bernd Wilhelmi, Hg., Umgangssprachen und Dialekte in der DDR, S. 114-128. (Wissenschaftliche Beiträge der Friedrich-Schiller-Universität Jena)

LÜGER Heinz-Helmut (1983): Pressesprache. Tübingen. (Germanistische Arbeitshefte; 28)

MICHEL Georg (1982): Zum Verhältnis von Sprechakt und Kommunikationsverfahren. Handlungstheoretische Positionen in der Linguistik der DDR. In: Zeitschrift für Phonetik, Sprachwissenschaft und Kommunikationsforschung, 35, 6, S. 685692.

MOSKALSKAJA Olga I. (1984): Textgrammatik. Leipzig. (Übersetzer und Herausgeber Hans Zikmund.)

NABRINGS Kirsten (1981): Sprachliche Varietäten. Tübingen.

NAIL Norbert (1985): Zeitungssprache und Massenpresse in der jüngeren Geschichte des Deutschen. In: Werner Besch-Oskar Reichmann-Stefan Sonderegger, Hg., Sprachgeschichte, Ein Handbuch zur Geschichte der deutschen Sprache und ihrer Erforschung. Berlin - New York, 2, S. 1663-1669.

NELLEN Frank P., Hg. (1986): Die Presse in Deutschland. Materialien zum Unterricht über das deutsche Pressewesen. (DAAD). Handschriftkopie.

POLENZ Peter von (1987): Nationale Varianten der deutschen Hochsprache. Podiumsdiskussion auf der 8. Internationalen Deutschlehrertagung in Bern am 5. August 1986. In: Zeitschrift für Germanistische Linguistik, 15, S. 101-103.

RATH Rainer (1985): Geschriebene und gesprochene Form der heutigen Standardsprache. In: Werner Besch-Oskar Reichmann- Stefan Sonderegger, Hg., Sprachgeschichte, Ein Handbuch zur Geschichte der deutschen Sprache und ihrer Erforschung. Berlin - New-York, 2, S. 1651-1663.

RONNEBERGER-SIBOLD Elke (1980): Sprachverwendung - Sprachsystem. Ökonomie und Wandel. Tübingen. (Linguistische Arbeiten; 87) 
SANDIG Barbara (1986): Stilistik der deutschen Sprache. Berlin - New-York. (Sammlung Göschen; 2229)

SCHILDT Joachim (1987): Die Beduetung von Textsorten für eine Theorie des Sprachwandels. In: Zeitschrift für Germanistik, 2, S. 187-198.

SCHMIDT Wilhelm (1982): Zum Funktionsbegriff 'in der neueren Linguistik, insbesondere in der funktional-kommunikativen Sprachbeschreibung. In: Zeitschrift für Phonetik, Sprachwissenschaft und Kommunikationsforschung, 35, 1, S. 9-18.

SCHMIDT Wilhelm et al. (1977): Sprache - Bildung und Erziehung. Leipzig.

SCHMIDT Wilhelm et al. (1981): Funktional-kommunikative Sprachbeschreibung. Theoretisch-methodische Grundlegung. Leipzig.

SORNIG Karl (1981): Soziosemantik auf der Wortebene. Stilistische Index-Leistung lexikalischer Elemente an Beispielen aus der Umgangssprache von Graz 73-78. Tübingen. (Linguistische Arbeiten; 102).

SPERLBAUM Margret (1975): Proben deutscher Umgangssprache. Tübingen.

STEGER Hugo (1984): Bemerkungen zum Problem der Umgangssprache. In: Ulrich Müller-Franz Hundsnurscher-Cornelius Sommer, $\mathrm{Hg}$., Festschrift für S. Grosse zum 60. Geburtstag. Göppingen, S. 251-279. (Göppinger Arbeiten zur Germanistik; 423)

STEWART William E. (1978): Die Reisebeschreibung und ihre Theoric im Deutschland des 18. Jahrhunderts. Bonn. (Literatur und Wirklichkeit; 20)

THIELE Rudolf (1983): Wilhelm Schmidt et al., Funktional-kommunikative Sprachbeschreibung. Theoretisch-methodische Grundlegung. In: Zeitschrift für Germanistik, 3, S. 355-357. Rezension.

VIEHWEGER Dieter, Hg. (1984): Grundfragen einer Theorie der sprachlichen Tätigkeit. Berlin. (Sprache und Gesellschaft; 13)

WAHRIG Gerhard (1986/87): Deutsches Wörterbuch. München.

WIESINGER Peter (1985): Die Entwicklung des Verhältnisses von Mundart und Standardsprache in Österreich. In: Werner Besch-Oskar Reichmann-Stefan Sonderegger, Hg., Sprachgeschichte, Ein Handbuch zur Geschichte der deutschen Sprache und ihrer Erforschung. Berlin - New-York, 2, S. 1939-1949. 


\section{KOMUNIKATIVNA FUNKCIJA SODOBNEGA NEMŠKEGA POGOVORNEGA JEZIKA V ČASOPISNIH POTOPISIH}

Disertacija želi dognati smotrnost rabe pogovornih jezikovnih prvin v pisnem jeziku in se pri tem omejuje na besedilno vrsto Casopisna pripoved kot konstanto. Pogovorni jezik kot predmet raziskave je $\mathrm{v}$ teoretičnem delu opredeljen $\mathrm{z}$ zgodovinskega, fenomenološkega in funkcionalnega vidika. Korpus tvorijo casopisna besedila, saj danes časopisni jezik bržčas najmočneje vpliva na normiranost jezika in na jezikovno kulturo uporabnikov. $V$ empiričnem delu skuša raziskava preko globinskih analitičnih postopkov ugotoviti, kakšna je funkcionalna povezanost med objektivnimi danostmi sporočevalnega položaja in med strategijo besediljenja. Predlagana klasifikacija komunikativnih funkcij pogovornih izrazil je metodični poskus sistematizacije, ki naj bi ga s pridom uporabili tudi v didaktične namene. Pri tem naj bi šlo

predvsem za izostritev posluha za problematiko komunikativno pogojene zvrstnosti jezika, presežen naj bi bil pristop, ki ima za edini cilj ukvarjanje s sistemskimi vprašanji jezika. 